\title{
Guidelines for liver transplantation for patients with non-alcoholic steatohepatitis
}

\author{
Philip Noel Newsome, ${ }^{1}$ M E Allison, ${ }^{2}$ P A Andrews, ${ }^{3}$ G Auzinger, ${ }^{4}$ C P Day, ${ }^{5}$ \\ J W Ferguson, ${ }^{6}$ P A Henriksen, ${ }^{7}$ S G Hubscher, ${ }^{8}$ H Manley, ${ }^{9}$ P J McKiernan, ${ }^{10}$ \\ C Millson, ${ }^{11}$ D Mirza, ${ }^{6} \mathrm{~J}$ M Neuberger, ${ }^{12} \mathrm{~J}$ Oben, ${ }^{13}$ S Pollard, ${ }^{11} \mathrm{~K}$ J Simpson, ${ }^{14}$ \\ D Thorburn, ${ }^{15} \mathrm{~J}$ W Tomlinson, ${ }^{16} \mathrm{~J} \mathrm{~S} \mathrm{Wyatt}{ }^{17}$
}

1Department of NIHR

Biomedical Research Unit and Centre for Liver Research, University of Birmingham, Birmingham, UK

${ }^{2}$ Department of Medicine, Cambridge University Hospital NHS Foundation Trust,

Cambridge, UK

${ }^{3}$ SW Thames Renal and

Transplantation Unit, London, UK ${ }^{4}$ Institute of Liver Studies, King's College Hospital, London, UK

${ }^{5}$ Liver Unit, University of

Newcastle, Newcastle, UK

${ }^{6}$ Liver Unit, University Hospital

Birmingham NHS Foundation

Trust, Birmingham, UK

${ }^{7}$ Department of Cardiology, Royal

Infirmary of Edinburgh,

Edinburgh, UK

${ }^{8}$ Department of Pathology,

University of Birmingham,

Birmingham, UK

${ }^{9}$ British Liver Trust, Ringwood, UK

${ }^{10}$ Liver Unit, Birmingham

Children's Hospital, Birmingham, UK

${ }^{11}$ Liver Unit, St James's University Hospital, Leeds, UK

${ }^{12} \mathrm{NHS}$ Blood and Transplant,

Bristol, UK

${ }^{13}$ Centre for Hepatology, University College London, London, UK

${ }^{14}$ Department of Hepatology, University of Edinburgh,

Edinburgh, UK

${ }^{15}$ Liver Unit, Royal Free Hospital,

London, UK

${ }^{16}$ Centre for Endocrinology,

Diabetes and Metabolism,

University of Birmingham,

Birmingham, UK

${ }^{17}$ Department of Pathology, St James's University Hospital, Leeds, UK

\section{Correspondence to}

Dr P N Newsome, Centre for

Liver Research, NIHR Biomedical Research Unit, Institute of Biomedical Research, University of Birmingham, Edgbaston, Birmingham B15 2TT, UK; p.n.newsome@bham.ac.uk

Revised 16 November 2011 Accepted 1 December 2011 Published Online First 10 January 2012

\section{GUIDELINE DEVELOPMENT}

Non-alcoholic steatohepatitis (NASH) is an increasing cause of liver disease necessitating liver transplantation. In patients with advanced NASH, there are often coexistent clinical issues that impact on the outcome of liver transplantation. There are no guidelines for the assessment and management of patients with NASH undergoing liver transplantation.

A group was therefore invited by the Council of the British Transplant Society (BTS) to prepare guidelines for the management of NASH before and after liver transplantation. The guideline is approved by the British Society of Gastroenterology, the British Association for the Study of Liver and NHS Blood and Transplant.

The first draft was written by Dr P N Newsome (senior lecturer and consultant hepatologist, Liver Unit, University Hospital Birmingham NHS Foundation Trust) in Autumn 2010 with contributions from the following guideline group: Dr Peter Henriksen (consultant cardiologist and honorary senior lecturer, Edinburgh Heart Centre, NHS Lothian, University Hospitals Division), Professor C P Day (Professor of Liver Medicine, Institute of Cellular Medicine, Newcastle University), Dr D Thorburn (consultant hepatologist, Liver Unit, Royal Free Hospital, London), Mr D F Mirza (consultant hepatobiliary and transplant surgeon, Liver Unit, University Hospital Birmingham NHS Foundation Trust), Dr J W Ferguson (consultant hepatologist and honorary senior lecturer, Liver Unit, University Hospital Birmingham NHS Foundation Trust), Dr G Auzinger (consultant intensive care medicine, Liver Intensive Therapy Unit, King's College Hospital London NHS Foundation Trust), Dr M Allison (consultant hepatologist, Liver Unit, Department of Medicine, Cambridge University Hospital NHS Foundation Trust), Dr J W Tomlinson (reader in endocrinology, Centre for Endocrinology, Diabetes and Metabolism, University of Birmingham), H Manley (British Liver Trust), Dr K J Simpson (senior lecturer in hepatology, University of Edinburgh and honorary consultant physician, Scottish Liver Transplantation Unit, Royal Infirmary Edinburgh), Professor S G Hubscher (Leith Professor and Professor of Hepatic Pathology, University of Birmingham, and consultant histopathologist, University Hospital Birmingham NHS Foundation Trust), Dr C Millson (consultant hepatologist, St James's University Hospital, Leeds), Dr J Oben (Wellcome Trust senior lecturer and consultant hepatologist, University College London, Centre for Hepatology, Royal Free Hospital, London), Professor J M Neuberger (Associate Medical Director for Organ Donation and Transplantation, NHS Blood and Transplant and honorary consultant physician, Queen Elizabeth Hospital, Birmingham), Dr P J McKiernan (consultant paediatrician, Liver Unit, Birmingham Children's Hospital) and Dr J I Wyatt (consultant histopathologist, St James's University Hospital, Leeds).

This followed a systematic review of the literature using retrieval from electronic databases and reading suggestions from colleagues. There was also significant input from the British Liver Trust across the whole document as well as the section on patient perspective.

The document was revised in the autumn and winter of 2010, principally by Dr P N Newsome and Dr P A Andrews (Chair, BTS Standards Committee). The last date of literature review was November 2010. A draft version was circulated to members of the BTS Council and placed on the BTS website for comment in March 2011 (http://www.bts.org.uk/ transplantation/standards-and-guidelines/). The final version was revised in the light of comments received in April 2011.

These guidelines represent consensus opinion from experts in the UK in the fields of hepatology, transplantation and related disciplines. They represent a snapshot of the evidence available at the time of writing. It is recognised that recommendations are made even when the evidence is weak, and indeed much of the evidence quoted is level C (consensus opinion) and so this document in many parts serves a consensus statement rather than clinical guidelines. However, as there is clear evidence in many sections and given that this document has been endorsed by the British Society of Gastroenterology, the British Association for the Study of Liver, BTS and UK and Ireland Transplant, it is felt the paper states a guideline. Although it is believed that the information presented is a fair summary of current evidence and best practice, neither the authors nor the BTS can be held responsible for any errors or omissions. The guidelines are not designed to be proscriptive, nor to define a standard of care. Doses of prescribed drugs should always be checked by the responsible clinician according to the relevant information provided by the manufacturers of the drugs.

It is anticipated that these guidelines will be revised in 2015. 


\section{GRADING OF RECOMMENDATIONS}

For each recommendation, assessments have been made of the quality of supporting evidence and the strength of the recommendation. This is in keeping with other national guideline groups. $^{1}$

For each recommendation, the quality of evidence has been graded as one of:

1. Level A-Data derived from multiple randomised clinical trials or meta-analyses.

2. Level B-Data derived from a single randomised trial or nonrandomised studies.

3. Level C-Consensus opinion of experts, case studies or standard of care.

For each recommendation, the strength of recommendation has been indicated as one of:

1. Class I-Conditions for which there is evidence and/or general agreement that a given evaluation, procedure or treatment is beneficial and effective.

2. Class II-Conditions for which there is conflicting evidence and/or a divergence of opinion about the usefulness/efficacy of an evaluation, procedure or treatment.

3. Class IIa-Weight of evidence/opinion is in favour of usefulness/efficacy.

4. Class IIb-Usefulness/efficacy is less well established by evidence/opinion.

5. Class III-Conditions for which there is evidence and/or general agreement that an evaluation/procedure/treatment is not useful/effective and in some cases may be harmful.

There are few data on transplant assessment of patients with $\mathrm{NASH}$ and therefore most recommendations are grade II or III and level $\mathrm{C}$.

\section{SUMMARY OF RECOMMENDATIONS}

Indications for liver transplantation in NASH related cirrhosis

1. Criteria for diagnosis of NASH group should include an established clinical and histological diagnosis of NASH on liver biopsy, or a histological diagnosis of cryptogenic cirrhosis with a clinical phenotype compatible with underlying NASH, as defined by the presence of three or more components of the metabolic syndrome prior to liver transplant (LT). (Level C, Class I).

2. Criteria for consideration of listing for LT in patients with NASH cirrhosis either due to end stage liver disease or presence of hepatocellular carcinoma should be in line with standard national criteria. (Level C, Class I).

\section{Assessment of operative risk in NASH patients undergoing liver transplant}

3. Although the diagnosis of NASH cirrhosis should not be regarded, in itself, to be a risk factor for poor outcome in the perioperative period of LT, cardiovascular risk should be closely considered in patients with NASH as they have more risk factors for cardiovascular disease and are likely to require further non-invasive testing. (Level C, Class I).

4. All NASH patients should undergo preoperative risk stratification to exclude symptomatic coronary artery disease and assessment for the presence of structural heart disease, left ventricular dysfunction and pulmonary hypertension. (Level C, Class I).

5. Patients unable to achieve four metabolic equivalence of tasks (METs), or those with at least one intermediate risk factor should be considered for further cardiac testing. (Level C, Class I).
6. Within a transplant centre, cardiology input should be provided by cardiologists with an interest/experience in the assessment of patients with liver disease. (Level C, Class I).

7. The following moderate risk groups should be discussed early with a cardiologist: (i) patients with chest pain of possible cardiac origin; and (ii) patients receiving treatment for established coronary disease or previous coronary revascularisation. (Level C, Class I).

8. There is insufficient evidence to recommend a single stress test for NASH patients undergoing LT assessment. The choice of test will be in part determined by local expertise. (Level C, Class I).

9. Patients without refractory ascites should be considered for a cardioselective $\beta$ blocker such as bisoprolol prior to LT. This should be titrated gradually and not started in the immediate perioperative period. Patients already receiving propanolol or carvedilol for prophylaxis against variceal bleeding should continue on those non-selective agents. (Level B, Class IIa).

10. Pravastatin should be considered in patients not already receiving a statin or continued in those patients already receiving it. Ideally, pravastatin should be started at least 1 week before surgery. Specifically, simvastatin and atorvastatin should be avoided in patients undergoing LT due to interactions with calcineurin inhibitors (CNIs). (Level B, Class I).

\section{Assessment and management of nutritional status during} transplant work-up

11. There are no data to support an absolute cut-off for body mass index (BMI) and LT although patients with a BMI $>40 \mathrm{~kg} / \mathrm{m}^{2}$ are likely to have an increased postoperative and long term mortality. BMI should be corrected for the presence of ascites and peripheral oedema. (Level C, Class IIa).

12. Weight loss should not be recommended in patients with decompensated end stage liver disease due to the risk of protein calorie malnutrition. (Level C, Class III).

13. For patients with compensated cirrhosis and hepatocellular carcinoma, it may be appropriate to try and achieve weight loss before proceeding/while waiting for a transplant. (Level C, Class II).

14. All potential NASH transplant recipients, including those with an elevated BMI, should be assessed by a dietician and supplemental feeding considered if protein calorie malnutrition is present. (Level C, Class I).

15. Dietary assessment of patients being assessed for LT should include use of handgrip strength, anthropometry and/or subjective global assessment to objectively define the patient's nutritional status and allow supplementation if required. (Level B, Class I).

16. Dietary assessment of patients should be repeated on an annual basis while they remain on the waiting list for LT. (Level B, Class I)

Surgical aspects of liver transplantation for patients with NASH

17. Consider bariatric surgery at the time of LT in recipients with severe morbid obesity, those with failed treatment of obesity or in patients with recurrent NASH undergoing retransplantation. (Level C, Class IIa)

18. Consider bariatric surgery in recipients with severe morbid obesity, those with failed treatment of obesity or in patients developing progressive NASH with fibrosis in the allograft. (Level C, Class IIa).

\section{Perioperative monitoring}

19. While there is likely to be an increased operative risk, the lack of evidence from controlled clinical trials indicates that no 
recommendation can be made about the use of intraoperative cardiac output monitoring. (Level B, Class II).

20. Moderately tight glucose control $(6-10 \mathrm{mmol} / \mathrm{l})$ should be targeted during the early post-transplant course in patients of all aetiologies. (Level A, Class II).

21. If started preoperatively, statin therapy should be continued during the postoperative phase. (Level B, Class I).

\section{Immunosuppression}

22. Alongside immunosuppression with $\mathrm{CNI}$ and antimetabolite, consideration should be given to either a steroid free regimen or early steroid withdrawal (within 3 months) in patients with NASH. Where steroid free regimens are used, induction therapy (such as antithymocyte globulin or interleukin 2 receptor antagonism) should be considered. (Level B, Class IIa).

23. Tacrolimus levels should be $5-8 \mathrm{ng} / \mathrm{ml}$ to reduce the impact on renal function and dyslipidaemia. Mycophenolate should be used as the preferred antimetabolite to permit lower levels of tacrolimus. (Level B, Class IIa).

24. Close follow-up and early recognition and treatment of the recognised consequences of transplantation and immunosuppression (such as weight gain, hypertension, hyperlipidaemia, diabetes and renal impairment) remain the key to preventing excess risk from recurrent NASH. (Level C, Class I).

\section{Post-transplant monitoring of NASH patients and disease recurrence}

25. Histological examination of the explanted liver should be carried out to confirm the presence of features compatible with end stage NASH and to exclude features suggesting an alternative diagnosis. (Level C, Class I).

26. The main role of biopsy is to the allow diagnosis and staging of liver histopathology. Where NASH is the only or dominant pathology, liver allograft biopsies can be scored using the Kleiner classification. Biopsies performed elsewhere should be reviewed at the transplant centre to ensure reproducibility. (Level C, Class I).

27. Post-transplant monitoring of patients should include an initial ultrasound (US) at 1 year, followed by every 2 years, looking for the presence of a fatty liver. (Level C, Class IIa).

28. Post-transplant monitoring of patients with a fatty liver on US should include protocol liver biopsies to detect disease recurrence, as liver function tests may be normal. Repeat biopsy should be considered every 3 years, unless there is a clinical indication for more frequent biopsies. (Level C, Class IIa).

\section{Post-transplant management of NASH}

29. Post-transplant patients should receive support, advice and treatment in order achieve a target BMI of $<25 \mathrm{~kg} / \mathrm{m}^{2}$. This should be in the context of a multidisciplinary team, incorporating dietary modification, exercise intervention and the potential use of pharmacotherapy and surgical intervention where appropriate. (Level C, Class I).

30. Post-transplant patients should be screened for the presence of diabetes and, if present, reviewed regularly for the development of complications. Glycaemic control should be optimised in accordance with the National Institute for Health and Clinical Excellence (NICE) guidance. (Level A, Class I).

31. Patients transplanted for NASH should be monitored on a 6 monthly basis for risk factors for cardiovascular disease (blood pressure (BP), lipids, haemoglobin A1c), which should be addressed with the intention of reducing cardiovascular events. (Level C, Class I).
32. A BP target of $140 / 90 \mathrm{~mm} \mathrm{Hg}(130 / 80 \mathrm{~mm} \mathrm{Hg}$ in patients with diabetes mellitus (DM) and/or renal dysfunction) should be aimed for (Level A, Class I).

33. Antihypertensive agents such as calcium channel blockers or angiotensin converting enzyme inhibitors should be considered in view of their possible additional effects of abrogating liver fibrosis. (Level C, Class II).

34. A target low density lipoprotein (LDL) cholesterol of $<2.6 \mathrm{mmol} / 1$ is advised as the 10 year cardiovascular event rate exceeds $20 \%$ for the liver transplant population. Pravastatin and ezetimibe are preferred agents in view of their demonstrated efficacy and absence of interactions with CNIs. (Level C, Class IIa).

\section{Transplantation for NASH-the patients' perspective}

35. There is a need to increase understanding of liver disease and its many causes, to improve patient outcomes and to reduce the stigma many patients experience. (Not graded).

36. The potential cardiovascular morbidity associated with NASH should be discussed with patients and guidance given on diet and exercise, and sources of support (including psychological support) as part of ongoing management. (Not graded).

37. Provision of independent pre- and post-transplant emotional and psychological counselling and support is very important, along with an opportunity to provide confidential feedback to the transplant team post-operatively. (Not graded).

\section{PREVALENCE OF NASH CIRRHOSIS IN THE UK}

Non-alcoholic fatty liver disease (NAFLD) encompasses a spectrum of disease ranging from simple steatosis to steatohepatitis (NASH) and cirrhosis. NAFLD is closely associated with obesity and represents the hepatic manifestation of the metabolic syndrome. The prevalence of NAFLD has risen rapidly in parallel with the dramatic rise in levels of obesity and $\mathrm{DM},{ }^{2}$ resulting in it now being the commonest cause of liver disease in the West. ${ }^{3}$

\section{NAFLD prevalence}

The prevalence of NAFLD is between $20 \%$ and $30 \%$ in Western adults, ${ }^{45}$ rising to $90 \%$ in extreme obesity. ${ }^{6}$ NAFLD affects $3 \%$ of the general paediatric population, rising to $53 \%$ in obese children, ${ }^{7}$ with implications for future disease burden. NASH, the more advanced and clinically important form of NAFLD, has an estimated prevalence of $2-3 \%$ in the general population ${ }^{9}$ and $37 \%$ in the morbidly obese. ${ }^{6}$ Steatosis was present in $70 \%$ of a large cohort of patients with type $2 \mathrm{DM}^{10}$ The Foresight report predicted that with the alarming growth of obesity, the burden of NAFLD on primary care and liver services will double from a current annual cost of $£ 4.2$ billion by 2050 . $^{11}$

\section{Association with increased mortality and progression to liver cirrhosis}

Patients with a diagnosis of NAFLD have been shown to have a significantly higher overall ${ }^{12-16}$ and liver related ${ }^{13}{ }^{14}$ mortality compared with an age and sex matched general population. In patients with NASH, the limited data available point to approximately one-third of patients developing progressive fibrosis over a 5 year period, with up to $9 \%$ developing cirrhosis. ${ }^{17} 18$ The risk factors for progressive NASH related liver disease are obesity, type $2 \mathrm{DM}$, insulin resistance and older age. Current evidence suggests that the natural history of NASH cirrhosis is similar to that of hepatitis C cirrhosis with respect to decompensation. ${ }^{19}{ }^{20} \mathrm{Hepa}-$ tocellular carcinoma (HCC), a recognised complication of cirrhosis 
of a number of aetiologies, is also known to occur in NASH related cirrhosis, and also rarely in precirrhotic $\mathrm{NASH}^{21} \mathrm{~A}$ prospective study on NASH cirrhotics has found a cumulative annual incidence of $2.6 \%$ for the development of HCC in this patient group compared with $4.0 \%$ for patients with hepatitis $\mathrm{C}$ virus (HCV) cirrhosis. $^{22}$ Obesity and DM have been found to be risk factors for the development of HCC in cirrhosis of a variety of aetiologies. ${ }^{23} 24$ The mortality of patients with NAFLD ranges from $12.6 \%$ over 7.6 years of follow-up in mixed cohorts to between $20.2 \%$ and $59.5 \%$ in secondary care cohorts (13.7-21 years of follow-up). In the most recent study with 21 years of follow-up, this corresponded to an excess mortality of $70 \%$ (standardised mortality ratio $1.7 ; 95 \%$ CI 1.24 to 2.25 ). ${ }^{15}$

\section{Need for liver transplantation}

The increase in the number of patients with advanced liver disease secondary to NASH, as well as associated HCC, will impact on the potential future demand for LT. Analysis of National Health Service Blood and Transplant (NHSBT) data shows that in both 2008 and 2009, 12\% of patients placed on the elective LT waiting list were categorised as having NASH cirrhosis, with $14.8 \%$ of these individuals with NASH listed with HCC. Consistent with the known association with insulin resistance, $49.1 \%$ of patients with NASH cirrhosis listed for LT were diabetic compared with $22.1 \%$ of all other registered patients (although the criteria for the definition of DM were not well defined).

\section{INDICATIONS FOR LIVER TRANSPLANTATION IN NASH RELATED CIRRHOSIS}

Given that LT is a relatively recently identified indication for patients with NASH, data for long term follow-up are more limited compared with LT for other causes of chronic liver disease. Nevertheless, data from several American centres suggest that patients with NASH do not have an inferior outcome 1, 2 and 5 years after LT when compared with other aetiologies of liver disease. ${ }^{25-27}$

There are no data to suggest that the natural history of cirrhosis after an initial clinical decompensation or the rate of change of Model for End Stage Liver Disease (MELD) score differ for patients with NASH compared with other causes of cirrhosis. Hence the current recommendation should be that there are no disease specific indications for listing for LT in this condition and that those currently used-that is, MELD score and/or specific variant indications (eg, diuretic resistant/ intolerant ascites) - should remain. In those patients with HCC on the background of NASH related cirrhosis, there are no data to support modification of the general criteria for listing for LT.

Many patients with end stage liver disease have a presumptive diagnosis of NASH. Patients may have a longstanding history or $\mathrm{DM}$ /hypertension with no other obvious reason for cirrhosis other than presumed previous NASH. Generally, when such patients present with liver decompensation they do not undergo liver biopsy, hence the need for standardisation of diagnosing $\mathrm{NASH}$. As such, in the absence of a histological diagnosis of $\mathrm{NASH}$, the presence of cirrhosis with a clinical phenotype compatible with underlying NASH, as defined by the presence of three or more components of the metabolic syndrome ${ }^{28}$ prior to LT, is sufficient.

Recommendation 1: Criteria for diagnosis of NASH should include an established clinical and histological diagnosis of NASH on liver biopsy, or a histological diagnosis of cryptogenic cirrhosis with a clinical phenotype compatible with underlying
$\mathrm{NASH}$, as defined by the presence of three or more components of the metabolic syndrome prior to LT. (Level C, Class I).

Recommendation 2: Criteria for consideration of listing for LT in patients with NASH cirrhosis either due to end stage liver disease or the presence of HCC should be in line with standard national criteria. (Level C, Class I).

In an era of significant organ shortage, with current mortality on the elective LTwaiting list being around 18\% in the UK, there is a duty to allocate organs responsibly. The national guidelines for adult LT are that patients should only be listed for LT if they have a predicted 5 year survival after transplantation of $\geq 50 \%$ (NHSBT Adult Liver Transplantation Guidelines 2009, accessed 19 February 2011 at http://www.organdonation.nhs.uk/ukt/ about_transplants/organ_allocation/liver/national_protocols_ and_guidelines/adults.jsp). Standard exclusion criteria will apply to NASH patients being considered for LT although their strong association with the metabolic syndrome will likely involve a more stringent assessment of cardiovascular risk.

There is not a large literature on the cost effectiveness of LT. Longworth et al compared the disease groups of alcohol, primary sclerosing cholangitis and primary biliary cirrhosis. ${ }^{29}$ They reported that the estimated gain in quality adjusted life years from transplantation was positive for each of the disease groups, and the mean incremental cost per quality adjusted life year ( $95 \%$ bootstrap confidence intervals) from time of listing to 27 months for patients with primary biliary cirrhosis, alcoholic liver disease and primary sclerosing cholangitis are $£ 29000$ ( $£ 1000$ to $£ 59000$ ), $£ 48000$ ( $£ 12000$ to $£ 83000$ ) and $£ 21000$ ( $-£ 23000$ to $£ 60000$ ), respectively. The higher cost in the alcoholic liver disease group was because a greater number of such patients were assessed for LT but not listed. There are no data looking at the cohort of NASH patients, although it is likely that the costs will be close to those seen in patients with alcoholic liver disease given concerns about cardiovascular risk. Their post-transplant outcomes are similar to those of other aetiologies so it is likely their cost effectiveness will be similar to that seen for indications such as alcoholic liver disease.

\section{Research/audit recommendations}

1. It would be helpful to calculate the cost effectiveness of LT for patients with NASH, with particular attention to the numbers needed to assess for each patient placed on the transplant list.

2. Data on use of marginal donors in this group should be recorded and compared with patients transplanted for other aetiologies.

\section{ASSESSMENT OF OPERATIVE RISK IN NASH PATIENTS UNDERGOING LIVER TRANSPLANTATION}

Having identified that a patient may benefit from LT, the next stage in the process involves an assessment of the risk to the patient of proceeding with the operation. The risks can be divided into short (up to 90 days) and long term (1 year onwards) to cover the immediate risks of the operation itself and then the longer term survival. In both of these categories there is concern that patients with NASH cirrhosis are at higher risk.

\section{Risk of cardiovascular events}

Cardiovascular risk factors are commonly found in patients undergoing LT, with hyperinsulinaemia, type II DM, hypertension, hyperlipidaemia and abdominal obesity disproportionately present in NASH patients. ${ }^{10}{ }^{30}$ Myocardial disease and dysfunction are common in cirrhotic patients. Indices of myocardial contractility such as left ventricular stroke work are 
increased at rest. ${ }^{31}$ A sustained increase in baseline cardiac output leads to cardiac hypertrophy and increases in left ventricular diastolic and left atrial pressures. ${ }^{31}$ Cirrhotic patients may have a normal resting ejection fraction but their reserve and ability to increase heart rate and cardiac output in response to stress are reduced, predisposing to decompensation during the anhepatic phase and following reperfusion. ${ }^{32} 33$

The above is of particular relevance to a significant proportion of patients with NASH related cirrhosis as they suffer from end organ damage from lipotoxicity and insulin resistance. The presence of pretransplant insulin treated DM has an adverse impact on long term post-transplant survival, ${ }^{34}$ and many individuals with NASH related cirrhosis have diabetic microvascular and macrovascular complications. Indeed, atherosclerosis has been found to be present in a higher proportion of patients with cirrhosis due to NASH compared with cirrhosis of other aetiologies. ${ }^{35}$ Other diabetic complications such as proliferative retinopathy, diabetic nephropathy, cardiovascular autonomic neuropathy and diabetic foot ulcer disease have also been shown to predict an increased morbidity/mortality in diabetic cohorts outside the context of organ transplantation. ${ }^{36-38}$ A further area of perceived increased risk relevant to the NASH cirrhotic population is that of the effect of obesity on LT outcome, which will be covered in the following section.

While there are data which suggest that NASH is an independent risk factor for cardiovascular disease, ${ }^{39}$ further large scale prospective studies are needed to draw firm conclusions about the independent hepatic contribution to the increased cardiovascular risk seen in patients with NASH. ${ }^{30}$ Notably, NASH has been reported to independently predict chronic kidney disease, which may explain part of the contribution to cardiovascular risk. ${ }^{40}$

Recommendation 3: Although the diagnosis of NASH cirrhosis should not be regarded, in itself, to be a risk factor for poor outcome in the perioperative period of LT, cardiovascular risk should be closely considered in patients with NASH as they have more risk factors for cardiovascular disease and are likely to require further non-invasive testing. (Level C, Class I).

\section{Cardiovascular event rate after liver transplantation}

Cardiovascular complications are a common cause of early morbidity and mortality after $\mathrm{LT}^{41}{ }^{42}$ Analysis of over 21000 patients undergoing LT in the European Liver Transplant Registry reported a 3 month mortality of $12 \%$, ${ }^{43}$ with $8 \%$ of deaths secondary to cardiac and a further $7 \%$ secondary to cerebrovascular causes. In a study of 413 patients of varying causes of end stage liver disease undergoing LT between 2001 and 2005, the 30 day all cause mortality was $9 \%$, with $7 \%$ developing a myocardial infarction (as defined by postoperative troponin elevation) within that time period. A history of previous stroke or coronary disease was associated with a 6.5fold and 4-fold increased risk of non-fatal myocardial infarction and death, respectively. ${ }^{44}$

Preoperative cardiac risk assessment relies on the presence of clinical risk markers, the patient's functional capacity and the extent or risk of the surgical procedure. LT is considered intermediate risk surgery compared with higher risk surgical procedures, such as aortic surgery, in European and American guidelines for preoperative cardiac risk assessment. ${ }^{45} 46$ However, the $1-5 \% 30$ day risk of myocardial infarction and cardiac death quoted for intermediate risk surgery in these guidelines ${ }^{45}$ is less than the rate of cardiovascular complications observed in many LT series ${ }^{47-49}$ suggesting that LT surgery should more probably be considered as moderate to high risk.

\section{Research/audit recommendations}

1. It is important to collect data on cardiovascular events for patients with NASH undergoing LT to establish if their event rate differs from cohorts transplanted for other indications.

2. To allow for appropriate comparisons, it is important to define what constitutes a cardiovascular event in terms of type of event and time since the operation.

\section{Preoperative selection and assessment}

\section{Phase I: looking for factors to risk stratify}

An accurate and reliable means of predicting short and long term post-LT progression in an individual is clearly desirable but not currently available. Several factors which confer increased risk have been identified (table 1) but data on their risk when added together are less clear. ${ }^{45}$ The history should seek to determine the patient's functional capacity, as assessment of the capacity to perform a range of common daily tasks has been shown to correlate well with maximum oxygen uptake on treadmill testing. ${ }^{50} \mathrm{MET}$ is an expression of energy expenditure during physical activity as a multiple of resting metabolic rate. One MET is considered as the resting metabolic rate, two METs would represent walking at a slow pace $(\mathrm{eg}, 3 \mathrm{~km} / \mathrm{h})$ and four METs would represent walking up two sets of stairs.

Preoperative cardiorespiratory assessment in patients with $\mathrm{NASH}$ does not differ to that routinely performed in other potential LT recipients. Standard tests include chest radiography, arterial blood gases, pulmonary function tests, 12 lead ECG and echocardiogram (with the following variables recorded: pulmonary artery systolic pressure, right ventricular function, left ventricular function, tricuspid regurgitation velocity and isovolumic relaxation time).

A retrospective analysis of patients transplanted with $\mathrm{NASH}$ cirrhosis found that the combination of age $\geq 60$ years, BMI $\geq 30 \mathrm{~kg} / \mathrm{m}^{2}, \mathrm{DM}$ and hypertension predicted a $50 \%$ mortality within 1 year of transplantation. ${ }^{26}$ This needs to be confirmed in larger cohorts but is consistent with another analysis of predictors of increased long term mortality post-LT. ${ }^{51}$ An attempt to incorporate comorbidity factors in a summative fashion to predict long term outcome after LT using a modified comorbidity index (Charlson Index) also found that the pretransplant presence of more than one defined risk factor for patients undergoing elective first transplantation resulted in a 5 year post-LT survival of $<50 \%$. ${ }^{52}$

Stratification of patients to various risk categories on the basis of risk markers varies across guidelines but one unifying principle is the assessment of a patient's functional state, as judged by METs. Both European ${ }^{45}$ and American ${ }^{53}$ guidelines of cardiovascular evaluation and care for patients undergoing non-cardiac surgery suggest that those with good functional

Table 1 Risk markers for cardiac decompensation during liver transplant surgery

\begin{tabular}{lll}
\hline Low risk & Intermediate risk & High risk \\
\hline No CVS risk factors & Angina pectoris & Acute heart failure \\
No comorbidities & Prior myocardial infarction & Symptomatic valvular \\
Good functional & Heart failure & heart disease \\
capacity ( $>4 \mathrm{METs})$ & Stroke/transient ischaemic & Significant pulmonary \\
& attack & hypertension \\
& Renal dysfunction (serum & Recent (within 30 days) \\
& creatinine $>170 \mu$ mol/l or & acute coronary syndrome \\
& $>2 \mathrm{mg} / \mathrm{dl}$ or a creatinine & and/or evidence of ongoing \\
& clearance of $<60 \mathrm{ml} / \mathrm{min}$ ) & myocardial ischaemia \\
& or need for renal support & Significant cardiac \\
& DM requiring insulin therapy & arrhythmias \\
\hline
\end{tabular}

CVS, cardiovascular; DM, diabetes mellitus; METs, metabolic equivalent of tasks. 
capacity (four or more METs) without symptoms do not require non-invasive testing prior to LT. This is in contrast with the American Association for the Study of Liver Diseases (AASLD) guidelines which recommend that potential LT recipients should undergo further cardiac investigation with dobutamine stress echocardiography and confirmatory angiography if they have any of the following factors: age $>50$ years, a history of chronic smoking, a past medical or family history of heart disease, or DM. $^{54}$

In the event that a patient's functional capacity is reduced to below four METs, the presence of between one ${ }^{53}$ and three ${ }^{45}$ intermediate risk factors are required to stratify a patient as moderate risk and therefore indicate the need for non-invasive testing

Acute heart failure, symptomatic valvular disease and pulmonary hypertension will generally preclude patients being listed for LT. Pulmonary hypertension is defined as a mean pulmonary artery pressure of $>25 \mathrm{~mm} \mathrm{Hg}$ at rest at cardiac catheterisation. ${ }^{55}$ It also requires a pulmonary capillary wedge pressure of $\leq 15 \mathrm{~mm} \mathrm{Hg}$ and a pulmonary vascular resistance of $\geq 240 \mathrm{dyn} / \mathrm{s} / \mathrm{cm}^{5}$. Portopulmonary hypertension is a separate indication for transplantation and will not be covered within these guidelines. Some of these conditions may respond to treatment, and options are expanding with improved management of heart failure and pulmonary hypertension, with some centres reporting successful combined cardiac and LT surgery.

Recommendation 4: All NASH patients should undergo preoperative risk stratification to exclude symptomatic coronary artery disease and assessment for the presence of structural heart disease, left ventricular dysfunction and pulmonary hypertension. (Level C, Class I).

Recommendation 5: Patients unable to achieve four METs, or those with at least one intermediate risk factor should be considered for further cardiac testing. (Level C, Class I)

An algorithm to aid in the investigation of cardiovascular risk patients with NASH cirrhosis being considered for LT is detailed in figure 1.

\section{Phase II: role of cardiac testing}

Assessment of functional capacity can be difficult in patients with end stage liver disease due to NASH because of the high incidence of reduced mobility, physical deconditioning and obesity. While risk stratification will determine the next level of cardiovascular investigation, early discussion with a cardiologist experienced in assessing cardiovascular risk in patients with end stage liver disease should be considered for more complex cases.

Recommendation 6: Within a transplant centre, cardiology input should be provided by cardiologists with an interest/ experience in the assessment of patients with liver disease. (Level C, Class I)

Recommendation 7: The following moderate risk groups should be discussed early with a cardiologist: (i) patients with chest pain of possible cardiac origin; and (ii) patients receiving treatment for established coronary disease or previous coronary revascularisation. (Level C, Class I)

The role of the cardiologist includes, but is not limited to, the following: (i) coronary angiography (invasive or by CT); (ii) functional testing with myocardial perfusion imaging; (iii) optimisation of pharmacotherapy; (iv) coronary revascularisation; and (v) advice on perioperative cardiac management in patients accepted for LT.

Cardiopulmonary exercise (CPX) testing predicts survival in LT candidates and following LT in general. CPX involves exercising on an upright bicycle, with assessment of the perfor-

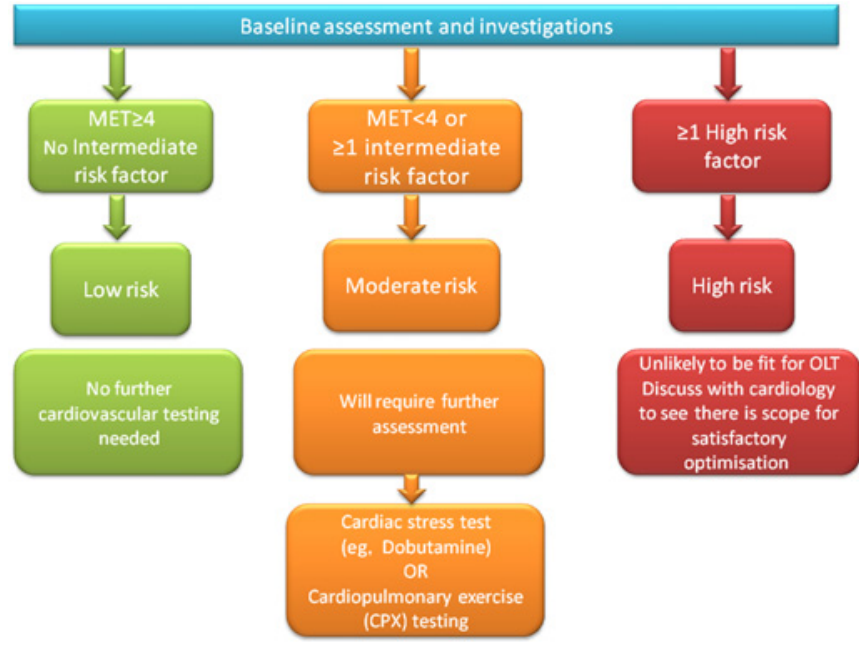

Figure 1 Assessment of cardiovascular risk in patients with nonalcoholic steatohepatitis (NASH) prior to liver transplantation. The number and severity of risk factors, as described in table 1, determines the risk category of a patient with NASH. This is also influenced by the metabolic equivalent of tasks (METs) that a patient can undertake. One MET is considered as the resting metabolic rate, two METs would represent walking at a slow pace $(\mathrm{eg}, 3 \mathrm{~km} / \mathrm{h})$ and four METs would represent walking up two sets of stairs. For those patients deemed to be at moderate risk, further investigation is required, preferably with some form of stress testing. OLT, orthotopic liver transplantation.

mance of both heart and lungs. In essence, it measures the point when exercise becomes anaerobic, and if this measurement is reduced, then operative risk is deemed to be high. In two studies, a threshold level of $<60 \%$ peak oxygen consumption during CPX independently predicted survival and length of hospital stay. ${ }^{56} 57$

Cardiac stress testing is directed towards establishing the presence of obstructive coronary disease but it appears to have a more limited predictive value for perioperative cardiac decompensation in this patient population compared with other high risk surgical groups. Dobutamine stress echocardiography (DSE), although moderately specific for coronary artery disease, lacks sensitivity in patients undergoing LT. ${ }^{59}$ Pre-existing high cardiac output in cirrhotics limits the value of DSE, and hence direct inotropic stimulation with the $\beta$ agonist dobutamine is preferential to the use of vasodilators such as adenosine or dypridamole. The vasodilated state of the patients with portal hypertension may attenuate the ability of vasodilators to increase coronary arterial blood flow but the theoretical advantage of dobutamine is often limited due to the concurrent administration of $\beta$ blockers and an inherent chronotropic incompetence found in some patients with chronic liver disease. $^{48}$ Guidelines on preoperative cardiac risk assessment indicate that patients with multiple cardiac risk markers or poor functional status undergoing high risk surgery are recommended for stress testing by perfusion imaging or DSE. ${ }^{45}$ Negative stress testing is reassuring, providing an excellent negative predictive value in patients undergoing major vascular surgery. ${ }^{60} 61$ The positive predictive value for perioperative myocardial infarction or death in this high risk surgery group is between $20 \%$ and $30 \%$ following a positive stress test. ${ }^{61}$ Perfusion imaging and DSE detect the presence of fixed obstructive coronary stenoses responsible for myocardial ischaemia during increased myocardial workload. The presence of obstructive coronary disease increases the risk of perioperative myocardial infarction but other factors 
contribute, including changes in coagulation and platelet activation during the perioperative period. ${ }^{62}$

According to Bayesian principles, the positive predictive value of a screening test depends on the prevalence of disease in the population tested. Patients with established vascular disease are more likely to have (asymptomatic) coronary disease than patients with liver cirrhosis. This may partly explain the comparably weak positive predictive value of DSE in LT patients. Studies have also reported poor discrimination for identifying patients at risk of perioperative troponin elevation and cardiac decompensation. ${ }^{59}$ "63 Many transplant centres use DSE as a preoperative screening test and the most recent AASLD guideline recommends DSE in smokers, patients with coronary disease or type II DM. ${ }^{54}$ A positive test mandates coronary angiography according to this guideline but patients with nonobstructed coronary arteries may still experience cardiac decompensation during $\mathrm{LT}^{64}$ The predictive value of other noninvasive methods such as ${ }^{99}$ Technetium labelled single photon emission computer tomographic studies is likewise poor. ${ }^{65}$

Calcification of coronary arteries on CT scanning is correlated with cardiovascular risk factors and the development of coronary atherosclerosis. Coronary calcification is seen in patients with the metabolic syndrome who are assessed for LT. ${ }^{66}$ Coronary calcium scoring may be used to further define the 10 year risk of cardiovascular events in asymptomatic populations. ${ }^{67}$ It does not provide information on the presence of obstructive coronary disease or inducible myocardial ischaemia and there is no evidence to support its use in perioperative risk assessment.

The above tests may aid in triaging patients in regards to diagnostic coronary investigations. Apart from standard invasive coronary angiography, CT coronary angiography is used with increasing frequency in the assessment of patients with possible cardiac chest pain. Despite the advantage of minimal invasiveness, it is limited in its ability to discriminate obstructive coronary lesions by the presence of coronary calcification and coronary stents. CT coronary angiography has been used to rule out coronary disease in patients undergoing heart valve surgery and non-cardiac surgery. Recent guidelines have suggested an application to further evaluate patients considered at intermediate risk of coronary disease undergoing non-cardiac surgery but it is currently not a recommended technique for perioperative risk assessment in non-cardiac surgery. ${ }^{45} 68$ Further research is required and no recommendation was given for this imaging modality in the most recent joint European Society of Cardiology and European Society of Anaesthesiology guideline on preoperative cardiac risk assessment. ${ }^{45}$

Recommendation 8: There is insufficient evidence to recommend a single stress test for NASH patients undergoing LT assessment. The choice of test will be in part determined by local expertise. (Level C, Class I).

Pharmacological risk reduction with $\beta$ blockers and statins has been extensively studied. Randomised trials selecting high risk patients, cohort studies and meta-analyses provide evidence supporting a decrease in cardiac mortality and myocardial infarction using cardioselective $\beta$ blockers in patients with clinical risk factors undergoing high and intermediate risk surgery. ${ }^{69}$ Treatment should be titrated and initiated ideally between 30 days and at least 1 week before surgery, with suggested targets of heart rate $60-70$ beats/min and systolic blood pressure $>100 \mathrm{~mm} \mathrm{Hg} .{ }^{45}$ Higher dose $\beta$ blockade started in the perioperative period was associated with increased mortality, reinforcing the need for gradual titrated introduction of therapy. ${ }^{70}$ Recent data have suggested that use of $\beta$ blockers in patients with refractory ascites is associated with poor survival and result in higher rates of paracentesis induced circulatory dysfunction, ${ }^{71} 72$ suggesting that $\beta$ blockers should be contraindicated in these patients.

Recommendation 9: Patients without refractory ascites should be considered for a cardioselective $\beta$ blocker such as bisoprolol prior to LT. This should be titrated gradually and not started in the immediate perioperative period. Patients already receiving propanolol or carvedilol for prophylaxis against variceal bleeding should continue on those non-selective agents. (Level B, Class IIa).

Similarly, starting statins has been shown to reduce cardiovascular mortality by $44 \%$ in meta-analyses in patients undergoing non-cardiac surgery. ${ }^{69} 73$ Stopping of statins may also result in a rebound effect and lead to increased cardiovascular complications. ${ }^{74}$ Pravastatin is the statin of choice as it is transformed enzymatically in the liver cytosol whereas all other statins undergo extensive microsomal metabolism by the cytochrome P450 (CYP) isoenzyme systems and thus have greater interactions with CNIs. ${ }^{75}$ Specifically, simvastatin and atorvastatin should be avoided in patients undergoing LT due to the interactions with CNIs resulting in rhabdomyolysis.

Recommendation 10: Pravastatin should be considered in patients not already receiving a statin or continued in those patients already receiving it. Ideally, pravastatin should be started at least 1 week before surgery. Specifically, simvastatin and atorvastatin should be avoided in patients undergoing LT due to interactions with CNIs. (Level B, Class I).

\section{ASSESSMENT AND MANAGEMENT OF NUTRITIONAL STATUS DURING TRANSPLANT WORKUP}

Perioperative morbidity and mortality is increased following major surgical procedures among the obese because of concomitant cardiovascular disease, hyperlipidaemia and pulmonary dysfunction. ${ }^{76}$ The AASLD practice guideline, among others, suggests that morbid obesity should be considered a contraindication to $\mathrm{LT}^{54} 77$

\section{Influence of obesity on postoperative liver transplant outcome}

A consistent drawback with the majority of studies examining the influence of obesity on transplant outcome has been that the amount of ascites/peripheral oedema has not been taken into account when calculating BMI. Table 2 details how weight can be adjusted for ascites and peripheral oedema. This is important given that ascites is a marker of disease severity. Of the 12 published studies, only Leonard's study ${ }^{79}$ measured ascites volume at transplantation and identified those with obesity as opposed to those with marked ascites. ${ }^{77}$ 79-89 A second drawback is that the conclusions are drawn only from those patients with obesity who have undergone transplantation, so extrapolation from these to all potential candidates may be misleading.

Analysis of the United Network for Organ Sharing database demonstrated that primary graft non-function and immediate, 1 year and 2 year mortality were significantly higher in the morbidly obese group $(\mathrm{p}<0.05)$. In addition, 5 year mortality was significantly higher in both severely and morbidly obese subjects $(p<0.05)$, mostly as a result of adverse cardiovascular

Table 2 Correction for fluid excess in body mass ${ }^{78}$

\begin{tabular}{lll}
\hline & Ascites/kg & Peripheral oedema/kg \\
\hline Minimal & 2.2 & 1 \\
Moderate & 6 & 5 (knees) \\
Severe & 14 or more & 10 (thigh) \\
\hline
\end{tabular}


events. ${ }^{77}$ Kaplan-Meier survival was significantly lower in morbidly obese patients, and morbid obesity was an independent predictor of mortality. Further analysis of the United Network for Organ Sharing database in 2009 drew broadly similar conclusions, although it suggested that obese patients (BMI $>40 \mathrm{mg} / \mathrm{kg}^{2}$ ) tended to be transplanted with more advanced MELD scores and hence these patients might be best served by receiving a graft at an earlier stage than non-morbidly obese counterparts. ${ }^{89}$ This is borne out by a large study of 29000 patients waitlisted for LTs which found that obese recipients waited longer and were more likely to be passed over. ${ }^{90}$ Looking at UK LT outcome data for patients with hepatitis C, a high BMI was an independent predictor of a worse outcome at 90 days, but not long term. ${ }^{91}$

The importance of correcting for ascites volume was demonstrated by Leonard et al, correction resulting in 11-20\% of patients moving into a lower BMI classification. ${ }^{79}$ The relative risk for mortality increased by $7 \%$ for each litre of ascites removed, with the conclusion that corrected BMI is not an independent predictor of patient or graft survival. This would suggest that obesity should not be considered to be an absolute contraindication to LT in the absence of other relative contraindications. The decision to list a patient will include an assessment of all potential relative contraindications, such as a BMI of $>40$.

Recommendation 11: There are no data to support an absolute cut-off for BMI and LT although patients with a BMI $>40 \mathrm{mg} / \mathrm{kg}^{2}$ are likely to have an increased postoperative and long term mortality. BMI should be corrected for the presence of ascites and peripheral oedema (Level C, Class IIa).

\section{Weight loss in liver transplant recipients}

There are no data on the following: (i) impact of weight loss pretransplant, (ii) data on intervention studies post-LT or (iii) strategies for maintaining weight loss in transplant recipients.

\section{Behaviour changes required for liver transplantation}

For tobacco, alcohol or illicit substances, a requirement for complete abstinence is widely accepted and enforceable, and adherence can be checked. Food, however, is a basic requirement which cannot be proscribed, and food restriction in patients with end stage liver disease is potentially harmful. Despite the appearance of obesity, some patients with advanced liver disease will have protein calorie malnutrition, and therefore should be fully assessed by a dietician for evidence of protein malnutrition. Dietary restriction risks worsening protein calorie malnutrition, and should only be contemplated under careful supervision by a dietician. Protein calorie malnutrition is associated with reduced graft and patient survival. ${ }^{92} \mathrm{~A}$ weight orientated contract after LT is superficially attractive, to mimic the existing no alcohol contract, but the practicalities would need careful consideration.

Recommendation 12: Weight loss should not be recommended in patients with decompensated end stage liver disease due to the risk of protein calorie malnutrition. (Level C, Class III).

Recommendation 13: For patients with compensated cirrhosis and HCC, it may be appropriate to try and achieve weight loss before proceeding/while waiting for a transplant. (Level C, Class II).

\section{Assessment of patient nutritional status}

Nutrition management in patients with advanced liver disease and obesity is problematic. Accurate estimation of nutritional status is difficult in patients with advanced liver disease, regardless of whether or not they are obese, in part due to poor interobserver reproducibility and overestimation of values because of third spacing of fluid. Protein calorie malnutrition is a condition of body wasting related to dietary deficiency of calories and protein, is found in $65-90 \%$ of patients with end stage liver disease ${ }^{93}$ and is associated with reduced graft and patient survival. ${ }^{92} 94$ The detection and management of protein calorie malnutrition is therefore an integral part of the dietary assessment.

Skinfold measurement and handgrip strength are simple tests of nutritional status, with the latter proving to be a good predictor of complications in patients with advanced liver disease. ${ }^{95}$ Other methods include the subjective global assessment, which combines multiple elements of nutritional assessment to classify the severity of malnutrition. ${ }^{96}$

In 1997, the European Society for Clinical Nutrition and Metabolism developed guidelines for meeting nutritional goals in patients with end stage liver disease. ${ }^{97}$ This included a diet consisting of $35 \%$ fat $(15-20 \%$ monosaturates, minimal trans fats, reduced saturated fats, $<10 \%$ total fat), $50 \%$ carbohydrate (minimal refined carbohydrate) and $15 \%$ protein. For obese patients with end stage liver disease, the transplant team should be aware that dietary restriction risks enhancing protein calorie malnutrition, and should only be contemplated under careful supervision by a dietician. If safe, calorie restriction should be limited to target no more than $0.5-1 \mathrm{~kg}(1-2 \mathrm{lb})$ weight loss per week and to avoid weight loss exceeding $1.5 \mathrm{~kg}$ per week. In some circumstances malnutrition may be present despite apparent obesity, in which case supplementation with night time tube feeding may be of value. ${ }^{98}$ Patients with well preserved liver function and small HCCs may benefit from weight loss but only if the delay does not adversely affect their cancer.

Recommendation 14: All potential NASH transplant recipients, including those with an elevated BMI, should be assessed by a dietician and supplemental feeding considered if protein calorie malnutrition is present. (Level C, Class I).

Recommendation 15: Dietary assessment of patients being assessed for LT should include use of handgrip strength, anthropometry and/or subjective global assessment to objectively define the patient's nutritional status, and start supplementation if required. (Level B, Class I).

Recommendation 16: Dietary assessment of patients should be repeated on an annual basis while they remain on the waiting list for LT. (Level B, Class I).

\section{SURGICAL ASPECTS OF LIVER TRANSPLANTATION FOR PATIENTS WITH NASH \\ Perioperative issues in NASH patients undergoing liver transplantation}

Patients undergoing LT for NASH pose additional challenges for surgical teams. As the potential donor pool continues to evolve, the use of extended criteria donors in NASH recipients needs to be assessed, especially donor grafts with moderately severe steatosis. Such patients are also less likely to be suitable recipients for split liver and living related transplantation as the segmental liver graft is more likely to be relatively small for size for the obese NASH recipient. Consequently, patients with NASH may have restricted access to the already severely limited donor organ pool, reducing their chances of undergoing LT.

Few data exist on the use of steatotic donor livers and their impact on the development of post-transplant recurrent NASH. As disease recurrence after LT is common and the diagnosis based on liver histology, the performance of a core liver biopsy 
after reperfusion and prior to abdominal closure is of value to provide baseline liver histology for comparison with late posttransplant biopsies. These biopsies may also assist the evaluation of patients with early graft dysfunction, which these grafts may be more predisposed to.

\section{Bariatric surgery at the time of transplantation}

LT surgery provides an opportunity to perform additional bariatric surgical procedures to facilitate weight loss and also limit the risk of recurrent disease. Such procedures do add an additional risk to what is already a high risk procedure. The presence of portal hypertension or post-reperfusion coagulopathy would be strong reasons to perform the least invasive additional bariatric surgical procedure. As a small proportion of LT patients may require a future Roux-en-Y biliary enteric anastomosis, it is preferable to limit bariatric procedures to non-bypass procedures. Similarly, the use of gastric bands in the setting of advanced liver disease and subsequent post LT immunosuppression may increase the risk of sepsis related to the device.

Almost no evidence exists on the role of bariatric surgery at the time of LT. It would therefore be logical to consider such an approach only in highly selected situations, possibly in recipients with severe morbid obesity, those with failed treatment of obesity or in patients with recurrent disease undergoing retransplantation. The choice of procedure should be guided by the status of the recipient at the end of the transplant procedure, the essential requirements being the presence of satisfactory early liver graft function, adequate haemostatic parameters, control of all bleeding and the availability of local bariatric surgical expertise. The use of less invasive options such as gastric balloons is potentially attractive, as this will keep the additional risks to a minimum. The intragastric balloon (IGB) is a safe, endoscopically placed, saline filled, silicone balloon which can remain in the stomach for up to 6 months. ${ }^{99}$ There are good efficacy data in non-transplant patients, such that some bariatric services use it as a firstline procedure and progress only to formal bariatric surgery if the IGB fails. The weight loss achievable by the IGB has been shown to be up to $32 \mathrm{~kg}$ after 6 months.

Portal hypertension is a contraindication to IGB placement and may limit its utility in early post-transplant patients. The rate of spontaneous deflation of the IGB is very low at $<0.1 \%$. In the unlikely event that the IGB does deflate unexpectedly, methylene blue dye admixed with the saline in the balloon will discolour the stool and so provide prompt evidence of leakage of the balloon contents.

Recommendation 17: Consider bariatric surgery at the time of LT in recipients with severe morbid obesity, those with failed treatment of obesity or in patients with recurrent NASH undergoing retransplantation. (Level C, Class IIa).

\section{Bariatric surgery after liver transplantation}

The LT recipient who remains morbidly obese or develops recurrent or de novo NASH may in the course of time be considered a candidate for bariatric surgery. Little or no data exist on the timing and selection of such patients for bariatric surgery. The vast majority of these patients will be on modest stable maintenance immunosuppression, and ideally would be off corticosteroids or on low dose maintenance corticosteroids. Most patients are on a combination of an antiproliferative agent (azathioprine or mycophenolate) and a CNI (tacrolimus or ciclosporin). Patients on mammalian target of rapamycin inhibitors (mTORi, sirolimus or everolimus) will need to stop these drugs 4 weeks before an operation as they are associated with impaired wound healing, and alternative regimens considered.
There are few data on which to base recommendations for patient and procedure selection for patients undergoing bariatric surgery post-LT. Extensive adhesions may make the laparoscopic approach difficult or sometime impossible, with a higher risk of open conversion and its additional risks. The use of intestinal bypass surgery may have an impact on future biliary enteric surgery and may also affect the absorption of immunosuppressive medication. In view of these issues, it is preferable to consider the use of endoscopic placed gastric balloons as the procedure of choice, followed by non-bypass gastric surgery as the next option. Case reports support the feasibility and efficacy of Roux-en-Y gastric bypass for recurrent NASH in LT recipients with morbid obesity. ${ }^{100}$

Recommendation 18: Consider bariatric surgery in recipients with severe morbid obesity, those with failed treatment of obesity or in patients with developing progressive NASH with fibrosis in allograft. (Level C, Class IIa).

\section{PERIOPERATIVE MONITORING}

The anhepatic and reperfusion phases during LT are associated with a high risk of cardiovascular instability. The former occurs due to a sudden reduction in venous return, and the latter because of the effects of the return of cold, acidotic and hyperkalaemic preservation fluid into the circulation. ${ }^{101}$ Release of vasoactive mediators and myocardial depression related to free oxygen radical production are additional pathogenetic mechanisms. The clinical picture is characterised by sudden onset of profound arterial hypotension due to the combined effects of reduction in systemic vascular resistance, increase in pulmonary vascular resistance and drop in heart rate and cardiac output.

Patients with NASH and associated cardiovascular risk factors may be particularly vulnerable to these effects, and advanced haemodynamic monitoring with pulmonary artery catheters (PAC) is routinely performed in many transplant centres. Despite the theoretical advantage of invasive perioperative monitoring and therapeutic guidance based on PAC data, randomised controlled trials in high risk surgery ${ }^{102}$ or in the critically ill ${ }^{103}$ have not shown any evidence of benefit. Indeed, there are no controlled data showing an advantage of PAC use, or indeed any other form of advanced haemodynamic monitoring tool, during LT.

Trans-oesophageal echocardiography provides immediate and direct assessment of cardiac structures and the functional status of both ventricles. It is an excellent tool to diagnose new onset regional wall motion abnormalities and enables assessment of the filling status of the left ventricle as well as estimation of pulmonary artery pressures. Compared with PAC it is relatively non-invasive and low risk; however, it is operator dependent and requires appropriate training. Whether intraoperative management based on trans-oesophageal echocardiography imaging provides any outcome benefit is unknown. The lack of continuous monitoring capability outside the operating theatre in the intensive care unit (ICU) is another potential drawback.

Recommendation 19: While there is likely to be an increased operative risk, the lack of evidence from controlled clinical trials indicates that no recommendation can be made about the use of intraoperative cardiac output monitoring. (Level B, Class II)

\section{Perioperative management of conditions frequently associated with NASH}

Insulin resistance, diabetes mellitus and blood sugar control

A linear relationship exists between blood sugar levels and adverse outcome in hospitalised patients, regardless of the presence of DM. A large single centre randomised controlled study published in 2001 showed a 42\% relative mortality 
reduction in surgical ICU patients when blood sugar levels were normalised to $4.4-6.1 \mathrm{mmol} / \mathrm{l}^{104}$ This was achieved by virtue of continuous insulin infusion in combination with hypercaloric parenteral nutrition. The control group only received therapy if the glucose level exceeded $11.9 \mathrm{mmol} / \mathrm{l}$. A minority of patients had a history of DM (13\%) and only $5 \%$ of patients were admitted following transplantation, which makes extrapolation of the findings to the post-LT setting difficult. Subsequent multicentre studies and a meta-analysis failed to reproduce the results of this trial, and concerns have been raised in regards to the possible harmful effects of tight glucose control through an increased incidence of life threatening hypoglycaemia.

The largest study to date from the Australian and New Zealand Intensive Care Society collaborators (Normoglycaemia in Intensive Care Evaluation-Survival Using Glucose Algorithm Regulation (NICE-SUGAR)), a multicentre randomised controlled trial, randomised more than 6000 patients to tight glucose control of $4.5-6 \mathrm{mmol} / 1$ versus $10 \mathrm{mmol} / 1$ or less. Surprisingly, intensive insulin therapy increased mortality in both medical and surgical patients, perhaps in association with an increased incidence of severe hypoglycaemia. ${ }^{105}$ In comparison with the earlier trial, patients were primarily enterally fed and they received significantly less calories and insulin; however, the blood sugar level in the control group was comparable, averaging $8 \mathrm{mmol} / \mathrm{l}$. In the absence of evidence in relation to perioperative blood sugar management in NASH and extrapolating from the available data pertaining to ICU patients, moderate glucose control targeting levels between 6 and $10 \mathrm{mmol} / \mathrm{l}$ is recommended.

Recommendation 20: Moderately tight glucose control $(6-10 \mathrm{mmol} / \mathrm{l})$ should be targeted during the early post-transplant course in patients of all aetiologies. (Level A, Class II).

\section{NASH and statin use in the perioperative period}

Dyslipidaemia is a common finding in patients with NASH and statins are widely used for this indication. Recent studies have extended the use of statins beyond traditional indications of lipid lowering therapy. Cholesterol independent therapeutic, pleiotropic effects of statins include anti-inflammatory and antioxidative properties, improvement of endothelial function and increased nitric oxide bioavailability. In addition to antiinflammatory properties, statins may interfere with the activation of the coagulation cascade and modulate platelet function. Several retrospective trials and prospective studies in patients undergoing vascular surgery have shown a beneficial effect of statins, with reduction in the incidence of perioperative myocardial infarction, coupled with an excellent safety profile. Several experimental and observational trials postulate a beneficial role of statins in sepsis, especially in patients with suspected bacterial infection. ${ }^{106}$

Patients already receiving statins should not have their treatment interrupted perioperatively or during the intensive care stay to maintain the beneficial pleiotropic effects and reduce the risk of cardiac events. ${ }^{107}$ As statins can interact with CNIs, careful attention should be paid to the choice and dose of statin used. Pravastatin is the statin of choice in view of it having the least interactions with CNIs. ${ }^{75}$

Recommendation 21: If started preoperatively, statin therapy should be continued during the postoperative phase. (Level B, Class I).

\section{IMMUNOSUPPRESSION}

Lifelong immunosuppression (IMS) is required in the great majority of patients following LT, irrespective of primary indi- cation. Overall, liver allograft recipients have an increased risk of morbidity and mortality from cardiac and cerebrovascular disease, weight gain and DM. ${ }^{108}$ Maintenance IMS regimens are based on either monotherapy with a CNI (ciclosporin or tacrolimus) or an mTORi (sirolimus or everolimus), or combination therapy with two or more of corticosteroids, CNI, mTORi and an antimetabolite (usually azathioprine or mycophenolate). The selection of the most appropriate regimen for the patient is likely to vary during the course of the lifetime of the graft and will depend on many factors, including the indication, likelihood and consequences of allograft rejection, and comorbid conditions. ${ }^{109}$

Although both recurrent and de novo NASH may develop in the allograft, there have been no significant prospective trials evaluating different IMS regimens in patients grafted for NASH. The selection of the most appropriate IMS regimen for the liver allograft recipient transplanted for NASH will depend on many factors, including:

- The time after transplant. In many cases, immunosuppression load can be reduced; many centres withdraw steroids by 3 months.

- Risk of rejection. This will depend on many factors, including the indication for transplantation, a history of early or late rejection and the response to increased immunosuppression.

- Comorbid conditions. For example, CNI may be reduced or avoided where there is renal impairment.

- Indication. mTORi may be preferred for those with liver cell cancer.

- Complications. CNIs may be reduced or avoided when renal impairment develops, and mycophenolate should be avoided when neutropenia develops.

Impact of immunosuppressive agents on risk factors for NASH The currently used agents all have differing impacts on components of the metabolic syndrome, as shown in table $3 .{ }^{51} 108-116$

Ciclosporin and tacrolimus have slightly differing effects on some of these risks: for example, new onset diabetes after transplantation is more common with tacrolimus than ciclosporin $^{110}$ while hyperlipidaemia is more common with ciclosporin. ${ }^{109}$ Due to superior patient outcome, tacrolimus is preferred to ciclosporin and is the firstline CNI used in clinical practice. $^{117}$

\section{Selection of an immunosuppressive regimen}

The prime goal of any immunosuppression regimen must be maintenance of normal graft function and prevention of graft damage from immune and other factors, with an acceptable side effect profile. However, the selection of specific combinations of immunosuppressive agents may allow a reduction of the risk of recurrence of NASH in the graft and the associated vascular and metabolic side effects.

While there are no prospective studies evaluating different immunosuppressive regimens in this context, the following may

Table 3 Impact of immunosuppressive agents on components of the metabolic syndrome and hepatic steatosis

\begin{tabular}{llllll}
\hline Class of agent & Hypertension & Dyslipidaemia & DM & Weight gain & $\begin{array}{l}\text { Hepatic } \\
\text { steatosis }\end{array}$ \\
\hline Corticosteroids & + & + & ++ & ++ & ++ \\
CNI & ++ & ++ & ++ & + & - \\
Antimetabolites & - & - & - & - & - \\
mTORi & - & +++ & $+/-$ & - & - \\
\hline
\end{tabular}

CNI, calcineurin inhibitor; mTORi, mammalian target of rapamycin inhibitors. 
be considered for those transplanted with or for the metabolic syndrome and/or NASH:

- Corticosteroids. Where possible, use either a steroid free regimen or early steroid withdrawal. Where steroid free regimens are used, induction therapy (such as antithymocyte globulin or interleukin 2 receptor antagonism) should be considered.

- CNIs. Although tacrolimus may be more strongly associated with DM than ciclosporin, it has a better effect on graft outcome.

- mTORi. Should be avoided as firstline agents although they may be indicated for those with liver cell cancer or as rescue therapy.

Several studies support use of antimetabolites such as mycophenolate to allow lower doses of tacrolimus and reduce the impact on DM and renal dysfunction. ${ }^{118-120}$ This is reinforced by data demonstrating that NASH patients develop worse renal dysfunction after transplant, even after DM and hypertension are taken into account. ${ }^{121}$

Recommendation 22: Alongside immunosuppression with $\mathrm{CNI}$ and an antimetabolite, consideration should be given to either a steroid free regimen or early steroid withdrawal (within 3 months) in patients with NASH. Where steroid free regimens are used, induction therapy (such as antithymocyte globulin or interleukin 2 receptor antagonism) should be considered. (Level B, Class IIa).

Recommendation 23: Tacrolimus levels should be 5-8 ng/ $\mathrm{ml}$ to reduce the impact on renal function and dyslipidaemia. Mycophenolate should be used as the preferred antimetabolite, to permit lower levels of tacrolimus. (Level B, Class IIa).

It is essential that modification of the immunosuppressive regimen should be considered in combination with lifestyle and pharmacological approaches to reducing the recurrence and impact of metabolic syndrome. This includes regular monitoring and treatment (where indicated) of DM, hypertension and hyperlipidaemia.

Recommendation 24: Close follow-up and early recognition and treatment of the recognised consequences of transplantation and immunosuppression (such as weight gain, hypertension, hyperlipidaemia, DM and renal impairment) remain the key to preventing excess risk from recurrent NASH. (Level C, Class I).

\section{POST-TRANSPLANT MONITORING OF NASH PATIENTS AND DISEASE RECURRENCE \\ NASH recurrence in the liver allograft}

Many studies have described histological features of recurrent fatty liver disease in patients transplanted for NASH. ${ }^{25} 27122-128$ Similar changes have also been observed in patients transplanted for conditions other than NASH. ${ }^{124} 125$ 129-134 Some of these patients were initially diagnosed as having cryptogenic cirrhosis at the time of listing but were subsequently found to have pretransplant risk factors for fatty liver disease while others presumably reflect transplant related risk factors that predispose to the metabolic syndrome.

Recommendation 25: Histological examination of the explanted liver should be carried out to confirm the presence of features compatible with end stage NASH and to exclude features suggesting an alternative diagnosis. (Class I, Level C).

\section{Histological assessment of NASH recurrence}

The histological features of NASH in the liver allograft are essentially the same as those occurring in the native liver. However, changes seen in post-transplant biopsies may be modified by a number of other complications of LT. The challenge to the pathologist is to distinguish whether all features are attributable to fatty liver disease or whether there is an additional post-transplant complication. Conditions that may have overlapping histological features with certain components of NASH include rejection, biliary complications and vascular/architectural changes, including nodular regenerative hyperplasia. ${ }^{135-137}$

Late rejection may lack the typical portal tract features of acute rejection and frequently includes centrilobular necroinflammatory changes ('central perivenulitis') that may be associated with hepatocyte ballooning and with the development of centrilobular fibrosis. Biliary complications are characterised by periportal ductular reaction and fibrosis, both of which have been described as features of NASH in the native liver. ${ }^{138}$ Nodular regenerative hyperplasia is an increasingly recognised finding in late post-transplant biopsies and may be associated with the development of perisinusoidal fibrosis in centrilobular regions. ${ }^{139}$ The latter sometimes occurs as an isolated finding without conspicuous nodularity. There are also interactions between HCV infection, insulin resistance and metabolic fatty liver disease, which may be important in the pathogenesis and severity of recurrent HCV infection and de novo NASH. ${ }^{132}{ }^{140-143}$ For this reason, biopsies performed elsewhere should be reviewed at the transplant centre.

Semiquantitative scoring systems are increasingly used to assess the severity of NASH in the native liver. ${ }^{144}$ The most widely used systems are those described by Brunt ${ }^{145}$ and Kleiner, ${ }^{146}$ both of which grade the severity of steatosis, hepatocyte ballooning and lobular inflammation, and stage the severity of fibrosis. Although several studies have assessed the histological severity of NASH in the liver allograft, the clinical utility of formal scoring systems in this context has not been validated. Problems may arise if there are coexistent graft complications that can mimic some of the NASH related features that are used for histological grading or staging. Scoring should therefore only be carried out if the changes seen can be attributed to NASH alone.

Recommendation 26: The main role of biopsy is to allow diagnosis and staging of liver histopathology. Where NASH is the only or dominant pathology, liver allograft biopsies can be scored using the Kleiner classification. Biopsies performed elsewhere should be reviewed at the transplant centre to ensure reproducibility. (Class I, Level C).

\section{Frequency and impact of NASH recurrence}

Fatty change occurs in $60-100 \%$ of patients within a few months of transplantation, and approximately $10-40 \%$ develop features of steatohepatitis, albeit usually not severe. Approximately $10 \%$ of patients progress to bridging fibrosis or cirrhosis by 10 years post-transplant. ${ }^{27}$ Likewise, features of fatty liver disease are commonly seen in protocol biopsies from patients transplanted for conditions other than NASH. ${ }^{134} 147148$ Onethird of patients with histological evidence of recurrent NASH have normal liver enzymes, which supports the role of protocol liver biopsies in monitoring disease progression in the liver allograft. ${ }^{127}$ While disease progression is rapid in occasional cases, resulting in graft failure within 2-3 years of transplantation, ${ }^{123}$ in the majority of cases recurrent NASH does not appear to have a major impact on graft survival in the first 5 years post-transplant. ${ }^{27} 149150$ However, the long term clinical importance of recurrent NASH is not yet known, and data from the pretransplant setting indicate that NASH confers a worse prognosis to that of simple steatosis over a 10-15 year period. 
Distinction between NASH and steatosis in the allograft should therefore result in a focus on changes in lifestyle advice and medical therapy.

Recommendation 27: Post-transplant monitoring of patients should include an initial US at 1 year, followed by every 2 years, looking for the presence of a fatty liver. (Class Ila, Level C).

Recommendation 28: Post-transplant monitoring of patients with a fatty liver on US should include protocol liver biopsies to detect disease recurrence, as liver function tests may be normal. Repeat biopsy should be considered every 3 years unless there is a clinical indication for more frequent biopsies. (Class IIa, Level C).

\section{Factors predicting NASH recurrence}

Cumulative steroid dose after LT has been shown to predict recurrence of $\mathrm{NASH}$ in the allograft ${ }^{25}$ but further work is required to identify whether other factors such as BMI, dyslipidaemia and diabetic status/control are also responsible. Use of angiotensin converting enzyme inhibitors has been suggested to reduce recurrence post-transplant. ${ }^{132}$

\section{Research/audit recommendation}

It will be important to compare non-invasive modalities for the assessment of NASH and fibrosis with liver biopsy post-LT.

\section{POST-TRANSPLANT MANAGEMENT OF NASH Obesity and weight management}

Patients transplanted for NASH are at an increased risk for the subsequent development of features of the metabolic syndrome. $\mathrm{New}$ onset obesity is reported in $17-43 \%$ of post-transplant patients. ${ }^{128} 151-153$ In addition, hypertension is reported in $35 \%$, impaired glucose tolerance/DM in $16 \%$, hypercholesterolaemia in $18 \%$ and hypertriglyceridaemia in $19 \%$ of patients. ${ }^{128}$ Overt post-transplant metabolic syndrome comprising a constellation of cardiovascular risk factors may be present in up to $58 \%$ of patients. ${ }^{109} 154155$ Importantly, 26\% of deaths in post-transplant NASH patients are due to cardiovascular causes ${ }^{128}$ and those patients with post-transplant metabolic syndrome have significantly more cardiovascular events than those without metabolic syndrome (30\% vs $8 \%)^{154}$

Morbidly obese patients (BMI $>40 \mathrm{~kg} / \mathrm{m}^{2}$ ) have a higher incidence of primary graft non-function post-transplant but this does not appear to impact on 1-2 year graft survival. However, 30 day, 1 year and 2 year mortality are significantly higher in morbidly obese patients. Five year mortality is increased in both severe (BMI $>35 \mathrm{~kg} / \mathrm{m}^{2}$ ) and morbid obesity but this is not a reflection of intraoperative mortality. Using a proportional hazards model of survival, 2 year survival is independently predicted by morbid obesity and type $2 \mathrm{DM}^{77}$

While it makes clinical sense to optimise weight management and reduce cardiovascular risk, there are currently no published studies that have examined the impact of weight reduction on outcome in patients transplanted for NASH. In a single study, $>90$ min of exercise per week was associated with improved quality of life outcomes as measured by the SF-36 questionnaire in post-LT patients although the precise indication for transplantation was not defined in this cohort. ${ }^{156}$

Recommendation 29: Post-transplant patients should receive support, advice and treatment in order achieve a target BMI of $<25 \mathrm{~kg} / \mathrm{m}^{2}$. This should be in the context of a multidisciplinary team, incorporating dietary modification, exercise intervention and the potential use of pharmacotherapy and surgical intervention where appropriate. (Level C, Class I).

\section{Insulin resistance and type 2 diabetes}

Studies have reported a variable prevalence of post-transplant DM and although some of the variability may be explained by different diagnostic criteria, values range from $13 \%$ to $61 \%{ }^{154}{ }^{157-159}$ The prevalence of DM in the post-transplant group is 6.0 times higher (95\% CI 4.2 to 8.4 ) than in age and sex matched control populations. ${ }^{160}$ Insulin resistance has been documented in almost all patients with pretransplant cirrhosis. ${ }^{161} 162$ After transplantation, insulin sensitivity improves, ${ }^{161-163}$ but importantly many patients (in excess of $40 \%$ ) remain insulin resistant. ${ }^{109}$

Patients with DM have increased mortality post-transplant in comparison with non-diabetic patients. ${ }^{34}$ While mortality in patients whose DM is controlled by diet alone is not increased in comparison with non-diabetic post transplant patients, those patients on oral agents and/or insulin therapy have increased mortality. ${ }^{164}$ More detailed outcome studies are urgently needed and there are currently no published data that have examined the impact of glycaemic control on outcome in patients transplanted for NASH.

Recommendation 30: Post-transplant patients should be screened for the presence of DM and, if present, reviewed regularly for the development of complications. Glycaemic control should be optimised in accordance with NICE guidance. (Level A, Class I).

\section{Cardiovascular risk}

There is a high incidence of cardiovascular events in LT recipients, with an increased standardised risk compared with a non-transplant population. ${ }^{41}$ Twenty-six per cent of deaths in post-transplant NASH patients are due to cardiovascular causes. ${ }^{128}$ Patients with post-transplant metabolic syndrome have significantly more cardiovascular events than those without metabolic syndrome (30\% vs $8 \%) .{ }^{154}$

Recommendation 31: Patients transplanted for NASH should be closely monitored on a 6 monthly basis for risk factors for cardiovascular disease (BP, lipids, haemoglobin A1c), which should be addressed with the intention of reducing cardiovascular events. (Level II-3, Level C Class I) (Level C, Class I).

\section{Hypertension}

The prevalence of hypertension after LT is significantly higher than that in the general population (standard prevalence ratio 3.07, 95\% CI 2.35 to 3.93). ${ }^{160}$ While accepted JNC-7 (Seventh Report of the Joint National Committee on Prevention, Detection, Evaluation and Treatment of High Blood Pressure) definitions of hypertension apply-that is $\mathrm{BP} \geq 140 / 90 \mathrm{~mm} \mathrm{Hg}$ - patients with type $2 \mathrm{DM}$, common in this population, and/or renal dysfunction, should have a target $\mathrm{BP}<130 / 80 \mathrm{~mm} \mathrm{Hg}$.

Non-pharmacological measures including weight reduction, salt restriction, physical activity and alcohol restriction are recommended despite the absence of specific trials. The aim of pharmacological therapy is to achieve the target $\mathrm{BP}$, and in the setting of LT there is evidence that calcium channel blockers, $\beta$ blockers and angiotensin converting enzyme inhibitors are efficacious in this respect. ${ }^{165-168}$ Specific agents may also confer additional benefits, such as reduction of proteinuria ${ }^{169}$ and prevention of liver fibrosis ${ }^{170}$ with angiotensin converting enzyme inhibitors, although these are not yet proven. ${ }^{171}$

Recommendation 32: A BP target of 140/90 mm Hg (130/ $80 \mathrm{~mm} \mathrm{Hg}$ in patients with DM and/or renal dysfunction) should be aimed for. (Level A, Class I).

Recommendation 33: Antihypertensive agents such as calcium channel blockers or angiotensin converting enzyme 
inhibitors should be considered in view of their possible additional effect of abrogating liver fibrosis. (Level C, Class II).

\section{Dyslipidaemia}

The prevalence of post-LT dyslipidaemia ranges from $66 \%$ to $85 \%$, usually with a mixed picture of elevated total cholesterol and triglycerides. ${ }^{172}$ Although standard treatment thresholds apply, a target LDL cholesterol of $<2.6 \mathrm{mmol} / \mathrm{l}$ is advised as the 10 year cardiovascular event rate exceeds $20 \%$ for the LT population. ${ }^{172}$ Therapeutic lifestyle changes are recommended, although not evidence based. Statins have been shown to be efficacious ${ }^{173}{ }^{174}$; however, consideration should be given to drug interactions (eg, ciclosporin and calcium channel blockers) which can be minimised with the use of pravastatin. ${ }^{108}$ Ezetimibe has been demonstrated to be effective at reducing serum cholesterol and to have few side effects and no interaction with immunosuppressive regimens. ${ }^{175}$ However, long term outcome studies are not yet available for this agent.

Recommendation 34: A target LDL cholesterol of $<2.6 \mathrm{mmol} / \mathrm{l}$ is advised as the 10 year cardiovascular event rate exceeds $20 \%$ for the LT population. Pravastatin and ezetimibe are preferred agents in view of their demonstrated efficacy and absence of interactions with CNIs. (Level C, Class IIa).

\section{NON-ALCOHOLIC FATTY LIVER DISEASE IN CHILDREN}

$\mathrm{NASH}$ is now the commonest liver disease in childhood, reflecting the global increase in childhood obesity. ${ }^{176} 177 \mathrm{NASH}$ currently affects approximately $10 \%$ of adolescents and up to $40 \%$ of obese adolescents. ${ }^{178}$ The majority of children who have undergone biopsy for suspected NASH have some degree of hepatic fibrosis. This is usually mild, but risk factors for increased fibrosis include age, the degree of obesity, male sex, ethnicity and hypopituitarism. ${ }^{176} 179$

Increased carotid artery intimal thickness occurs in children with NASH and they have also been shown to have increased mortality. ${ }^{180}{ }^{181}$ It is unclear at present whether the presence of $\mathrm{NASH}$ is itself an independent risk factor for cardiovascular disease in obese children.

There are four published cases of paediatric transplantation for $\mathrm{NASH}^{181-183}$ In two cases the primary aetiology was hypopituitarism, and all four cases had hepatopulmonary syndrome as the immediate indication for transplantation. All survived, but recurrence of NASH with significant fibrosis was universal within the first year. In one case this required repeat transplantation after 3 years. Another case was treated with metformin and initial moderate fibrosis resolved 3 years post-transplant.

\section{Pre-transplant assessment}

Investigations should include routine pretransplant assessment but in addition should focus on components of the metabolic syndrome, including fasting lipid profile, hyperuricaemia, hypertension and evaluation of pituitary function. Specific screening for hepatopulmonary syndrome including, as a minimum, saturation monitoring, is indicated. At present there is insufficient evidence to justify formal invasive screening for cardiovascular disease.

\section{Indications for transplantation}

These are similar to those for end stage liver disease of any cause.

\section{Management post-transplantation}

No specific evidence guidelines can be recommended; however, in the absence of autoimmune disease, steroid administration should be minimised. It would appear sensible to minimise calcineurin inhibition by the use of antimetabolites such as mycophenolate or azathioprine.

\section{Monitoring}

Evidence based recommendations cannot be given. Good practice would suggest active monitoring for components of the metabolic syndrome and protocol liver biopsies at 1, 5 and 10 years post-transplant.

\section{De novo post-transplant NASH}

This may well turn out to be a quantitatively more important issue than NASH as a primary indication for LT, given the high incidence of obesity following transplantation. However, although current long term studies suggest that fibrosis is a common finding in late post-transplant biopsies, in these cases it does not appear to be related to the development of fatty liver disease. ${ }^{184} 185$ Longer follow-up of patients who have become obese after LT will provide insights on the burden of de novo NASH.

\section{TRANSPLANTATION FOR NASH-THE PATIENTS' PERSPECTIVE Improving awareness and reducing stigma}

Patient feedback suggests that opportunities for early intervention and diagnosis in patients with key risk factors for NASH, such as obesity, DM and insulin resistance, are being missed, leading to unnecessary disease progression. Many patients also report a degree of stigma associated with liver disease in the public's perception. This can be very difficult for patients and families to deal with and can make them feel very isolated. Patients, and in particular family members, say they would have liked to have been forewarned about the symptoms of advanced liver disease and not just been given information on the transplant process. Many mention hepatic encephalopathy as being particularly distressing and feel that understanding the cause would have reduced this distress.

Recommendation 35: There is a need to increase understanding of liver disease and its many causes, to improve patient outcomes and reduce the stigma many patients experience. (Not graded).

Patients diagnosed with NASH, particularly those who do not have obvious symptoms of the metabolic syndrome, report confusion or lack of information on their diagnosis, its cause and what they can do to manage and improve their condition. With appropriate advice, management and support, patients can make lifestyle changes, improve liver health and avoid transplantation. Many patients struggle to maintain lifestyle changes in the long term. Many receive ongoing monitoring for clinical symptoms but no support for maintaining lifestyle changes.

Some patients believe they will be a 'different person' posttransplant and can find it difficult to come to terms with ongoing health problems. Those who suffered from depression, stress or eating disorders prior to transplant can find themselves falling back into old patterns.

It is important that patients understand the cardiovascular risks associated with both NASH and LT and what they can do to reduce these. Family members have a key role in supporting patients pre- and post-transplant, particularly with understanding and managing diet and being aware of symptoms. It is important that they are given information and involved in decisions.

Recommendation 36: The potential cardiovascular morbidity associated with NASH should be discussed with patients and guidance given on diet and exercise, and sources of support (including psychological support) as part of ongoing management. (Not graded). 


\section{Psychological impact}

The emotional and psychological impacts of the transplant process are significant and can be particularly difficult for people without good support from family and friends, or for those who have suffered from depression before transplantation. Patients can find it helpful to be put in touch with people who have previously been through the transplant experience, often as part of support groups. People who receive a transplant say they struggle to put into words the gratitude they feel towards the transplant team and the donor family. They therefore find it difficult to raise any complaints directly with the transplant team. Some patients (and their family members) have difficulty post-transplant in coming to terms with a transplanted organ. Patients also report experiencing flashbacks to their time in intensive care and say that they find it difficult to discuss these feelings with the transplant teams. The need for confidential emotional and psychological support is often raised by patients and carers.

Recommendation 37: Provision of independent pre- and post-transplant emotional and psychological counselling and support is very important, along with an opportunity to provide confidential feedback to the transplant team postoperatively. (Not graded).

This patient feedback was collated from British Liver Trust helpline enquiries, case studies, contacts and transplant support groups.

Acknowledgements The authors thank Kerri Barber, Principal Statistician, Statistics and Clinical Audit, NHS Blood and Transplant for analysing the NHSBT data relating to LT for NASH related cirrhosis. Dr K Agarwal contributed to discussions regarding this guideline. Professor Kevin Moore kindly provided editorial/ clinical advice on the guidelines on behalf of the BSG Guidelines committee.

Competing interests PNN has received travel and meeting expenses, but has not received lecture fees or contributed to advisory boards, from Astellas, Novartis, Pfizer and Roche. He has received no support from other agencies with a known interest in the development of these guidelines. His research and that of close collaborators has been in part sponsored by Novo Nordisk. PAA has received travel and meeting expenses, but has not received lecture fees or contributed to advisory boards, from Astellas, Novartis, Pfizer and Roche. He has received no support from other agencies with a known interest in the development of these guidelines. SP has received travel and meeting expenses from Astellas, Roche and Novartis over the past 18 years and was on the advisory board of Novartis until 2002. He has received no support from other agencies with a known interest in the development of these guidelines. CPD has received travel and meeting expenses from Astellas, Roche and Novartis and has been on the advisory boards for NASH of Astellas, Pfizer, GSK and Synageva. DT has received travel and meeting expenses, but has not received lecture fees or contributed to advisory boards, from Astellas, Novartis, Pfizer and Roche. He has received no support from other agencies with a known interest in the development of these guidelines. JWF has received travel and meeting expenses, but has not received lecture fees or contributed to advisory boards, from Astellas and Roche. He has received no support from other agencies with a known interest in the development of these guidelines. GA has received lecture fees from Pfizer (Anti-Infectives Division) and contributed to advisory boards from Pfizer, Gilead and MSD. He has received no support from other agencies with a known interest in the development of these guidelines. MEA has received travel and meeting expenses, but has not received lecture fees or contributed to advisory boards, from Astellas, Novartis, Pfizer and Roche. He has received no support from other agencies with a known interest in the development of these guidelines. HM (British Liver Trust): the British Liver Trust has received support from Astellas and Roche in the form of educational grants to enable the Trust to carry out its mission and activities. JMN has received speaker support from Astellas and Novartis and was a principal investigator for a Roche funded clinical trial. He has received no support from other agencies with a known interest in the development of these guidelines.

Provenance and peer review Not commissioned; externally peer reviewed.

\section{REFERENCES}

1. O'Shea RS, Dasarathy S, McCullough AJ. Alcoholic liver disease. Hepatology 2010:51:307-28.
2. Vuppalanchi R, Chalasani N. Nonalcoholic fatty liver disease and nonalcoholic steatohepatitis: selected practical issues in their evaluation and management. Hepatology 2009:49:306-17.

3. de Alwis NM, Day CP. Non-alcoholic fatty liver disease: the mist gradually clears. $J$ Hepatol 2008; (48 Suppl 1):S104-12

4. Browning JD, Szczepaniak LS, Dobbins R, et al. Prevalence of hepatic steatosis in an urban population in the United States: impact of ethnicity. Hepatology 2004; $40: 1387-95$

5. Bedogni G, Miglioli L, Masutti F, et al. Prevalence of and risk factors for nonalcoholic fatty liver disease: the Dionysos nutrition and liver study. Hepatology 2005; 42:44-52.

6. Machado M, Marques-Vidal P, Cortez-Pinto H. Hepatic histology in obese patients undergoing bariatric surgery. J Hepatol 2006;45:600-6.

7. Tominaga K, Kurata JH, Chen YK, et al. Prevalence of fatty liver in Japanese children and relationship to obesity. An epidemiological ultrasonographic survey. Dig Dis Sci 1995; 40:2002-9.

8. Franzese A, Vajro P, Argenziano A, et al. Liver involvement in obese children. Ultrasonography and liver enzyme levels at diagnosis and during follow-up in an Italian population. Dig Dis Sci 1997;42:1428-32.

9. Neuschwander-Tetri BA, Bellezzo JM, Britton RS, et al. Thiol regulation of endotoxin-induced release of tumour necrosis factor alpha from isolated rat Kupffer cells. Biochem J 1996;320:1005-10.

10. Targher G, Bertolini L, Padovani R, et al. Prevalence of nonalcoholic fatty liver disease and its association with cardiovascular disease among type 2 diabetic patients. Diabetes Care 2007:30:1212-18.

11. Aylott J, Brown I, Copeland R, et al. Tackling obesities: The Foresight Report. Faculty of Health and Wellbeing; Sheffield Hallam University, 2007.

12. Angulo $\mathbf{P}$. Long-term mortality in nonalcoholic fatty liver disease: is liver histology of any prognostic significance? Hepatology 2010;51:373-5.

13. Ekstedt M, Franzen LE, Mathiesen UL, et al. Long-term follow-up of patients with NAFLD and elevated liver enzymes. Hepatology 2006:44:865-73.

14. Adams LA, Lymp JF, St SJ, et al. The natural history of nonalcoholic fatty liver disease: a population-based cohort study. Gastroenterology 2005:129:113-21.

15. Soderberg C, Stal P, Askling J, et al. Decreased survival of subjects with elevated liver function tests during a 28-year follow-up. Hepatology 2010;51:595-602.

16. Ong JP, Pitts A, Younossi ZM. Increased overall mortality and liver-related mortality in non-alcoholic fatty liver disease. J Hepatol 2008;49:608-12.

17. Fassio $\mathbf{E}$, Alvarez $\mathrm{E}$, Dominguez $\mathrm{N}$, et al. Natural history of nonalcoholic steatohepatitis: a longitudinal study of repeat liver biopsies. Hepatology 2004; 40:820-6

18. Adams LA, Sanderson S, Lindor KD, et al. The histological course of nonalcoholic fatty liver disease: a longitudinal study of 103 patients with sequential liver biopsies. $J$ Hepatol 2005;42:132-8.

19. Hui JM, Kench JG, Chitturi S, et al. Long-term outcomes of cirrhosis in nonalcoholic steatohepatitis compared with hepatitis C. Hepatology 2003:38:420-7.

20. Yatsuji S, Hashimoto E, Tobari M, et al. Clinical features and outcomes of cirrhosis due to non-alcoholic steatohepatitis compared with cirrhosis caused by chronic hepatitis C. J Gastroenterol Hepatol 2009:24:248-54.

21. Starley BO, Calcagno CJ, Harrison SA. Nonalcoholic fatty liver disease and hepatocellular carcinoma: a weighty connection. Hepatology 2010;51:1820-32.

22. Ascha MS, Hanouneh IA, Lopez R, et al. The incidence and risk factors of hepatocellular carcinoma in patients with nonalcoholic steatohepatitis. Hepatology 2010;51:1972-8.

23. Veldt BJ, Chen W, Heathcote EJ, et al. Increased risk of hepatocellular carcinoma among patients with hepatitis $\mathrm{C}$ cirrhosis and diabetes mellitus. Hepatology 2008:47:1856-62.

24. Polesel J, Zucchetto A, Montella M, et al. The impact of obesity and diabetes mellitus on the risk of hepatocellular carcinoma. Ann Oncol 2009;20:353-7.

25. Contos MJ, Cales W, Sterling RK, et al. Development of nonalcoholic fatty liver disease after orthotopic liver transplantation for cryptogenic cirrhosis. Liver Transp 2001:7:363-73

26. Malik SM, deVera ME, Fontes $\mathrm{P}$, et al. Outcome after liver transplantation for NASH cirrhosis. Am J Transplant 2009;9:782-93.

27. Yalamanchili K, Saadeh S, Klintmalm GB, et al. Nonalcoholic fatty liver disease after liver transplantation for cryptogenic cirrhosis or nonalcoholic fatty liver disease. Liver Transp/ 2010:16:431-9.

28. Grundy SM, Cleeman JI, Daniels SR, et al. Diagnosis and management of the metabolic syndrome: an American Heart Association/National Heart, Lung, and Blood Institute Scientific Statement. Circulation 2005:112:2735-52.

29. Longworth L, Young T, Buxton MJ, et al. Midterm cost-effectiveness of the liver transplantation program of England and Wales for three disease groups. Liver Transp/ 2003:9:1295-307.

30. Targher G, Day CP, Bonora E. Risk of cardiovascular disease in patients with nonalcoholic fatty liver disease. N Engl J Med 2010;363:1341-50.

31. Milani A, Zaccaria R, Bombardieri G, et al. Cirrhotic cardiomyopathy. Dig Liver Dis 2007;39:507-15.

32. Valeriano V , Funaro $S$, Lionetti $R$, et al. Modification of cardiac function in cirrhotic patients with and without ascites. Am J Gastroenterol 2000;95:3200-5.

33. Wong $\mathbf{F}$, Girgrah N, Graba J, et al. The cardiac response to exercise in cirrhosis. Gut 2001;49:268-75. 
34. Samuelson AL, Lee $\mathbf{M}$, Kamal $A$, et al. Diabetes mellitus increases the risk of mortality following liver transplantation independent of MELD score. Dig Dis Sci 2010;55:2089-94.

35. Kadayifci A, Tan V, Ursell PC, et al. Clinical and pathologic risk factors for atherosclerosis in cirrhosis: a comparison between NASH-related cirrhosis and cirrhosis due to other aetiologies. J Hepatol 2008:49:595-9.

36. Juutilainen A, Lehto $S$, Ronnemaa $T$, et al. Retinopathy predicts cardiovascular mortality in type 2 diabetic men and women. Diabetes Care 2007;30:292-9.

37. Pinto A, Tuttolomondo A, Di RD, et al. Cardiovascular risk profile and morbidity in subjects affected by type 2 diabetes mellitus with and without diabetic foot. Metabolism 2008;57:676-82.

38. Ghanassia E, Villon L, Thuan Dit Dieudonne JF, et al. Long-term outcome and disability of diabetic patients hospitalized for diabetic foot ulcers: a 6.5-year followup study. Diabetes Care 2008;31:1288-92.

39. Targher G, Bertolini L, Rodella S, et al. Nonalcoholic fatty liver disease is independently associated with an increased incidence of cardiovascular events in type 2 diabetic patients. Diabetes Care 2007;30:2119-21.

40. Targher G, Chonchol M, Zoppini G, et al. Risk of chronic kidney disease in patients with non-alcoholic fatty liver disease: is there a link? J Hepatol 2011:54:1020-9.

41. Johnston SD, Morris JK, Cramb R, et al. Cardiovascular morbidity and mortality after orthotopic liver transplantation. Transplantation 2002;73:901-6.

42. Plotkin JS, Scott VL, Pinna A, et al. Morbidity and mortality in patients with coronary artery disease undergoing orthotopic liver transplantation. Liver Transp/ Surg 1996;2:426-30.

43. Burroughs AK, Sabin CA, Rolles K, et al. 3-month and 12-month mortality after first liver transplant in adults in Europe: predictive models for outcome. Lancet 2006; 367:225-32.

44. Safadi A, Homsi M, Maskoun W, et al. Perioperative risk predictors of cardiac outcomes in patients undergoing liver transplantation surgery. Circulation 2009;120:1189-94

45. Poldermans D, Bax JJ, Boersma E, et al. Guidelines for pre-operative cardiac risk assessment and perioperative cardiac management in non-cardiac surgery: the Task Force for Preoperative Cardiac Risk Assessment and Perioperative Cardiac Management in Non-cardiac Surgery of the European Society of Cardiology (ESC) and European Society of Anaesthesiology (ESA). Eur Heart $J$ 2009:30:2769-812.

46. Eagle KA, Berger PB, Calkins $\mathrm{H}$, et al. ACC/AHA guideline update for perioperative cardiovascular evaluation for noncardiac surgery-executive summary a report of the American College of Cardiology/American Heart Association Task Force on Practice Guidelines (Committee to Update the 1996 Guidelines on Perioperative Cardiovascular Evaluation for Noncardiac Surgery). Circulation 2002;105:1257-67.

47. Fouad TR, Abdel-Razek WM, Burak KW, et al. Prediction of cardiac complications after liver transplantation. Transplantation 2009;87:763-70.

48. Umphrey LG, Hurst RT, Eleid MF, et al. Preoperative dobutamine stress echocardiographic findings and subsequent short-term adverse cardiac events after orthotopic liver transplantation. Liver Transp/ 2008;14:886-92.

49. Donovan CL, Marcovitz PA, Punch JD, et al. Two-dimensional and dobutamine stress echocardiography in the preoperative assessment of patients with end-stage liver disease prior to orthotopic liver transplantation. Transplantation 1996;61:1180-8.

50. Hlatky MA, Boineau RE, Higginbotham MB, et al. A brief self-administered questionnaire to determine functional capacity (the Duke Activity Status Index). Am J Cardiol 1989:64:651-4.

51. Watt KD, Pedersen RA, Kremers WK, et al. Evolution of causes and risk factors for mortality post-liver transplant: results of the NIDDK long-term follow-up study. Am J Transplant 2010:10:1420-7.

52. Volk ML, Hernandez JC, Lok AS, et al. Modified Charlson comorbidity index for predicting survival after liver transplantation. Liver Transp/ 2007:13:1515-20.

53. Fleisher LA, Beckman JA, Brown KA, et al. ACC/AHA 2007 guidelines on perioperative cardiovascular evaluation and care for noncardiac surgery: executive summary: a report of the American College of Cardiology/American Heart Association Task Force on Practice Guidelines (Writing Committee to Revise the 2002 Guidelines on Perioperative Cardiovascular Evaluation for Noncardiac Surgery). Anesth Analg 2008;106:685-712.

54. Murray KF, Carithers RL Jr. AASLD practice guidelines: evaluation of the patient for liver transplantation. Hepatology 2005:41:1407-32.

55. Badesch DB, Champion HC, Sanchez MA, et al. Diagnosis and assessment of pulmonary arterial hypertension. J Am Coll Cardiol 2009;54(Suppl 1):S55-66.

56. Dharancy S, Lemyze M, Boleslawski E, et al. Impact of impaired aerobic capacity on liver transplant candidates. Transplantation 2008;86:1077-83.

57. Epstein SK, Freeman RB, Khayat A, et al. Aerobic capacity is associated with 100day outcome after hepatic transplantation. Liver Transp/ 2004:10:418-24.

58. Harinstein ME, Flaherty JD, Ansari AH, et al. Predictive value of dobutamine stress echocardiography for coronary artery disease detection in liver transplant candidates. Am J Transplant 2008:8:1523-8.

59. Williams K, Lewis JF, Davis G, et al. Dobutamine stress echocardiography in patients undergoing liver transplantation evaluation. Transplantation 2000;69:2354-6.

60. Poldermans D, Arnese M, Fioretti PM, et al. Improved cardiac risk stratification in major vascular surgery with dobutamine-atropine stress echocardiography. J Am Coll Cardiol 1995:26:648-53.

61. Shaw LJ, Eagle KA, Gersh BJ, et al. Meta-analysis of intravenous dipyridamolethallium-201 imaging (1985 to 1994) and dobutamine echocardiography (1991 to
1994) for risk stratification before vascular surgery. J Am Coll Cardiol 1996;27:787-98.

62. Landesberg G, Beattie WS, Mosseri M, et al. Perioperative myocardial infarction. Circulation 2009;119:2936-44.

63. Findlay JY, Keegan MT, Pellikka PP, et al. Preoperative dobutamine stress echocardiography, intraoperative events, and intraoperative myocardial injury in liver transplantation. Transplant Proc 2005;37:2209-13.

64. Tsutsui JM, Mukherjee S, Elhendy A, et al. Value of dobutamine stress myocardial contrast perfusion echocardiography in patients with advanced liver disease. Liver Transp/ 2006;12:592-9.

65. Zoghbi GJ, Patel AD, Ershadi RE, et al. Usefulness of preoperative stress perfusion imaging in predicting prognosis after liver transplantation. Am J Cardiol 2003;92:1066-71

66. McAvoy NC, Kochar N, McKillop G, et al. Prevalence of coronary artery calcification in patients undergoing assessment for orthotopic liver transplantation. Liver Transp/ 2008;14:1725-31

67. Greenland $\mathbf{P}$, Bonow RO, Brundage BH, et al. ACCF/AHA 2007 clinical expert consensus document on coronary artery calcium scoring by computed tomography in global cardiovascular risk assessment and in evaluation of patients with chest pain: a report of the American College of Cardiology Foundation Clinical Expert Consensus Task Force (ACCF/AHA Writing Committee to Update the 2000 Exper consensus document on Electron Beam computed tomography) developed in collaboration with the Society of Atherosclerosis Imaging and Prevention and the Society of Cardiovascular Computed Tomography. J Am Coll Cardiol 2007:49:378-402.

68. Taylor AJ, Cerqueira M, Hodgson JM, et al. ACCF/SCCT/ACR/AHA/ASE/ASNC/ NASCI/SCAI/SCMR 2010 appropriate use criteria for cardiac computed tomography: a report of the American College of Cardiology Foundation Appropriate Use Criteria Task Force, the Society of Cardiovascular Computed Tomography, the American College of Radiology, the American heart association, the American Society of Echocardiography, the American Society of Nuclear cardiology, the North American Society for Cardiovascular Imaging, the Society for Cardiovascular Angiography and Interventions, and the Society for Cardiovascular Magnetic Resonance. J Am Coll Cardiol 2010:56:1864-94.

69. Dunkelgrun M, Boersma E, Schouten 0, et al. Bisoprolol and fluvastatin for the reduction of perioperative cardiac mortality and myocardial infarction in intermediate-risk patients undergoing noncardiovascular surgery: a randomized controlled trial (DECREASE-IV). Ann Surg 2009;249:921-6.

70. Devereaux PJ, Yang $H$, Yusuf $S$, et al. Effects of extended-release metoprolol succinate in patients undergoing non-cardiac surgery (POISE trial): a randomised controlled trial. Lancet 2008;371:1839-47.

71. Serste T, Melot C, Francoz C, et al. Deleterious effects of beta-blockers on survival in patients with cirrhosis and refractory ascites. Hepatology 2010;52:1017-22.

72. Serste T, Francoz C, Durand F, et al. Beta-blockers cause paracentesis-induced circulatory dysfunction in patients with cirrhosis and refractory ascites: a cross-over study. J Hepatol 2011;55:794-9.

73. Hindler K, Shaw AD, Samuels J, et al. Improved postoperative outcomes associated with preoperative statin therapy. Anesthesiology 2006;105:1260-72.

74. Schouten 0, Hoeks SE, Welten GM, et al. Effect of statin withdrawal on frequency of cardiac events after vascular surgery. Am J Cardiol 2007;100:316-20.

75. Bellosta S, Paoletti R, Corsini A. Safety of statins: focus on clinical pharmacokinetics and drug interactions. Circulation 2004;109(23 Suppl 1):III50-7.

76. Choban PS, Flancbaum L. The impact of obesity on surgical outcomes: a review. $J$ Am Coll Surg 1997;185:593-603.

77. Nair S, Verma S, Thuluvath PJ. Obesity and its effect on survival in patients undergoing orthotopic liver transplantation in the United States. Hepatology 2002;35:105-9

78. Madden A, Wicks C. A practical guide to nutrition in liver disease. Birmingham: Liver Interest Group of the British Dietetic Association, 1994.

79. Leonard J, Heimbach JK, Malinchoc M, et al. The impact of obesity on long-term outcomes in liver transplant recipients-results of the NIDDK liver transplant database. Am J Transplant 2008;8:667-72.

80. Braunfeld MY, Chan S, Pregler J, et al. Liver transplantation in the morbidly obese. J Clin Anesth 1996:8:585-90.

81. Sawyer RG, Pelletier SJ, Pruett TL. Increased early morbidity and mortality with acceptable long-term function in severely obese patients undergoing liver transplantation. Clin Transplant 1999:13:126-30.

82. Nair S, Cohen DB, Cohen MP, et al. Postoperative morbidity, mortality, costs, and long-term survival in severely obese patients undergoing orthotopic liver transplantation. Am J Gastroenterol 2001;96:842-5.

83. Mazuelos F, Abril J, Zaragoza C, et al. Cardiovascular morbidity and obesity in adult liver transplant recipients. Transplant Proc 2003:35:1909-10.

84. Rustgi VK, Marino G, Rustgi S, et al. Impact of body mass index on graft failure and overall survival following liver transplant. Clin Transplant 2004;18:634-7.

85. Hillingso JG, Wettergren $A$, Hyoudo $M$, et al. Obesity increases mortality in liver transplantation-the Danish experience. Transp/ Int 2005;18:1231-5.

86. Fujikawa T, Fujita S, Mizuno S, et al. Clinical and financial impact of obesity on the outcome of liver transplantation. Transplant Proc 2006;38:3612-14.

87. Pelletier SJ, Schaubel DE, Wei G, et al. Effect of body mass index on the survival benefit of liver transplantation. Liver Transp/ 2007:13:1678-83.

88. Hade AM, Shine AM, Kennedy NP, et al. Both under-nutrition and obesity increase morbidity following liver transplantation. Ir Med J 2003;96:140-2. 
89. Dick AA, Spitzer AL, Seifert CF, et al. Liver transplantation at the extremes of the body mass index. Liver Transp/ 2009;15:968-77.

90. Segev DL, Thompson RE, Locke JE, et al. Prolonged waiting times for liver transplantation in obese patients. Ann Surg 2008;248:863-70.

91. Dawwas MF, Allison ME, Watson CJ, et al. Diabetic donor organs and survival among $\mathrm{Hcv}+$ liver transplant recipients: a further piece in the jigsaw. Hepatology 2008; $48: 314 A-15$

92. Stickel F, Inderbitzin D, Candinas D. Role of nutrition in liver transplantation for endstage chronic liver disease. Nutr Rev 2008:66:47-54.

93. Henkel AS, Buchman AL. Nutritional support in patients with chronic liver disease. Nat Clin Pract Gastroenterol Hepatol 2006;3:202-9.

94. Klidjian AM, Archer TJ, Foster KJ, et al. Detection of dangerous malnutrition JPEN J Parenter Enteral Nutr 1982;6:119-21.

95. Alvares-da-Silva MR, Reverbel da ST. Comparison between handgrip strength, subjective global assessment, and prognostic nutritional index in assessing malnutrition and predicting clinical outcome in cirrhotic outpatients. Nutrition 2005;21:113-17.

96. Detsky AS, McLaughlin JR, Baker JP, et al. What is subjective global assessment of nutritional status? JPEN J Parenter Enteral Nutr 1987:11:8-13.

97. Plauth M, Merli M, Kondrup J, et al. ESPEN guidelines for nutrition in liver disease and transplantation. Clin Nutr 1997;16:43-55.

98. Plank LD, Gane EJ, Peng S, et al. Nocturnal nutritional supplementation improves total body protein status of patients with liver cirrhosis: a randomized 12-month trial. Hepatology 2008;48:557-66.

99. Genco A, Cipriano M, Bacci V, et al. BioEnterics Intragastric Balloon (BIB): a shortterm, double-blind, randomised, controlled, crossover study on weight reduction in morbidly obese patients. Int J Obes (Lond) 2006;30:129-33.

100. Duchini A, Brunson ME. Roux-en-Y gastric bypass for recurrent nonalcoholic steatohepatitis in liver transplant recipients with morbid obesity. Transplantation 2001;72:156-9.

101. Ozier Y, Klinck JR. Anesthetic management of hepatic transplantation. Curr Opin Anaesthesiol 2008;21:391-400.

102. Sandham JD, Hull RD, Brant RF, et al. A randomized, controlled trial of the use of pulmonary-artery catheters in high-risk surgical patients. N Engl J Med 2003;348:5-14.

103. Harvey S, Harrison DA, Singer M, et al. Assessment of the clinical effectiveness of pulmonary artery catheters in management of patients in intensive care (PAC-Man): a randomised controlled trial. Lancet 2005;366:472-7.

104. Van den Berghe G, Wouters $P$, Weekers $F$, et al. Intensive insulin therapy in the critically ill patients. N Engl J Med 2001;345:1359-67.

105. Finfer S, Chittock DR, Su SY, et al. Intensive versus conventional glucose control in critically ill patients. N Engl J Med 2009;360:1283-97.

106. Gao F, Linhartova L, Johnston AM, et al. Statins and sepsis. Br J Anaesth 2008:100:288-98.

107. Merx MW, Weber C. Statins in the intensive care unit. Curr Opin Crit Care 2006;12:309-14.

108. Mells G, Neuberger J. Long-term care of the liver allograft recipient. Semin Liver Dis 2009:29:102-20.

109. Bianchi G, Marchesini G, Marzocchi R, et al. Metabolic syndrome in liver transplantation: relation to etiology and immunosuppression. Liver Transpl 2008; 14:1648-54.

110. Kuo HT, Sampaio MS, Ye X, et al. Risk factors for new-onset diabetes mellitus in adult liver transplant recipients, an analysis of the Organ Procurement and Transplant Network/United Network for Organ Sharing database. Transplantation 2010;89:1134-40.

111. Rossetto A, Bitetto D, Bresadola V, et al. Cardiovascular risk factors and immunosuppressive regimen after liver transplantation. Transplant Proc 2010;42:2576-8.

112. Desai S, Hong JC, Saab S. Cardiovascular risk factors following orthotopic liver transplantation: predisposing factors, incidence and management. Liver Int 2010:30:948-57.

113. Deleuze S, Garrigue V, Delmas S, et al. New onset dyslipidemia after renal transplantation: is there a difference between tacrolimus and cyclosporine? Transplant Proc 2006;38:2311-13.

114. Pageaux GP, Faure $\mathrm{S}$, Bouyabrine $\mathrm{H}$, et al. Long-term outcomes of liver transplantation: diabetes mellitus. Liver Transp/ 2009:(15 Suppl 2):S79-82

115. Wawrzynowicz-Syczewska M, Karpinska E, Jurczyk K, et al. Risk factors and dynamics of weight gain in patients after liver transplantation. Ann Transplant 2009:14:45-50.

116. Guckelberger 0, Mutzke F, Glanemann M, et al. Validation of cardiovascular risk scores in a liver transplant population. Liver Transp/ 2006;12:394-401.

117. O'Grady JG, Burroughs A, Hardy P, et al. Tacrolimus versus microemulsified ciclosporin in liver transplantation: the TMC randomised controlled trial. Lancet 2002; 360:1119-25.

118. Biselli M, Vitale G, Gramenzi A, et al. Two yr mycophenolate mofetil plus low-dose calcineurin inhibitor for renal dysfunction after liver transplant. Clin Transplant 2009:23:191-8.

119. Cicinnati VR, Yu Z, Klein CG, et al. Clinical trial: switch to combined mycophenolate mofetil and minimal dose calcineurin inhibitor in stable liver transplant patients-assessment of renal and allograft function, cardiovascular risk factors and immune monitoring. Aliment Pharmacol Ther 2007;26 $1195-208$
120. Pageaux GP, Rostaing L, Calmus $Y$, et al. Mycophenolate mofetil in combination with reduction of calcineurin inhibitors for chronic renal dysfunction after liver transplantation. Liver Transpl 2006;12:1755-60.

121. Houlihan DD, Armstrong MJ, Davidov $Y$, et al. Renal function in patients transplanted for NASH cirrhosis: time to reconsider immunosuppression regimens? Liver Transp/ 2011:17:1292-8.

122. Kim WR, Poterucha JJ, Porayko MK, et al. Recurrence of nonalcoholic steatohepatitis following liver transplantation. Transplantation 1996;62:1802-5.

123. Charlton M, Kasparova P. Weston S, et al. Frequency of nonalcoholic steatohepatitis as a cause of advanced liver disease. Liver Transp/ 2001;7:608-14.

124. Ong J, Younossi ZM, Reddy V, et al. Cryptogenic cirrhosis and posttransplantation nonalcoholic fatty liver disease. Liver Transp/ 2001:7:797-801.

125. Ayata G, Gordon FD, Lewis WD, et al. Cryptogenic cirrhosis: clinicopathologic findings at and after liver transplantation. Hum Pathol 2002;33:1098-104.

126. Sutedja DS, Gow PJ, Hubscher SG, et al. Revealing the cause of cryptogenic cirrhosis by posttransplant liver biopsy. Transplant Proc 2004;36:2334-7.

127. Malik SM, Devera ME, Fontes P, et al. Recurrent disease following liver transplantation for nonalcoholic steatohepatitis cirrhosis. Liver Transp/ 2009;15:1843-51.

128. Bhagat V, Mindikoglu AL, Nudo CG, et al. Outcomes of liver transplantation in patients with cirrhosis due to nonalcoholic steatohepatitis versus patients with cirrhosis due to alcoholic liver disease. Liver Transpl 2009;15:1814-20.

129. Garcia RF, Morales E, Garcia CE, et al. Recurrent and de novo non-alcoholic steatohepatitis following orthotopic liver transplantation. Arq Gastroenterol 2001; 38:247-53.

130. Poordad F, Gish R, Wakil A, et al. De novo non-alcoholic fatty liver disease following orthotopic liver transplantation. Am J Transplant 2003;3:1413-17.

131. Lim LG, Cheng CL, Wee A, et al. Prevalence and clinical associations of posttransplant fatty liver disease. Liver Int 2007:27:76-80.

132. Seo S, Maganti K, Khehra M, et al. De novo nonalcoholic fatty liver disease after liver transplantation. Liver Transp/ 2007;13:844-7.

133. Pagadala M, Dasarathy S, Eghtesad B, et al. Posttransplant metabolic syndrome: an epidemic waiting to happen. Liver Transp/ 2009;15:1662-70.

134. Dumortier J, Giostra E, Belbouab S, et al. Non-alcoholic fatty liver disease in liver transplant recipients: another story of "seed and soil". Am J Gastroenterol 2010;105:613-20

135. Demetris AJ, Adeyi 0, Bellamy CO, et al. Liver biopsy interpretation for causes of late liver allograft dysfunction. Hepatology 2006:44:489-501.

136. Hubscher SG. Transplantation pathology. Semin Liver Dis 2009;29:74-90.

137. Hubscher $\mathbf{S}$. What does the long-term liver allograft look like for the pediatric recipient? Liver Transpl 2009;(15 Suppl 2):S19-24.

138. Richardson MM, Jonsson JR, Powell EE, et al. Progressive fibrosis in nonalcoholic steatohepatitis: association with altered regeneration and a ductular reaction. Gastroenterology 2007:133:80-90.

139. Krasinskas A. The significance of nodular regenerative hyperplasia in the transplanted liver. Liver Transp/ 2007:13:1496-7.

140. Alsatie M, Pandya P, Chalasani NP. Insulin resistance, hepatitis C, and liver transplantation. Liver Transp/ 2008:14:136-7.

141. Cotler SJ, Kallwitz E, TenCate V, et al. Diabetes and hepatic oxidative damage are associated with hepatitis $\mathrm{C}$ progression after liver transplantation. Transplantation 2007:84:587-91.

142. Delgado-Borrego A, Liu YS, Jordan SH, et al. Prospective study of liver transplant recipients with HCV infection: evidence for a causal relationship between HCV and insulin resistance. Liver Transpl 2008;14:193-201.

143. Abdelmalek MF, Diehl AM. De novo nonalcoholic fatty liver disease after liver transplantation. Liver Transp/ 2007:13:788-90.

144. Hubscher SG. Histological assessment of non-alcoholic fatty liver disease. Histopathology 2006:49:450-65.

145. Brunt EM, Janney CG, Di Bisceglie AM, et al. Nonalcoholic steatohepatitis: a proposal for grading and staging the histological lesions. Am J Gastroenterol 1999;94:2467-74.

146. Kleiner DE, Brunt EM, Van Natta M, et al. Design and validation of a histologica scoring system for nonalcoholic fatty liver disease. Hepatology 2005;41:1313-21.

147. Abraham SC, Poterucha JJ, Rosen CB, et al. Histologic abnormalities are common in protocol liver allograft biopsies from patients with normal liver function tests. Am $J$ Surg Pathol 2008;32:965-73.

148. Mells G, Mann C, Hubscher S, et al. Late protocol liver biopsies in the liver allograft: a neglected investigation? Liver Transp/ 2009;15:931-8.

149. Rowe IA, Webb K, Gunson BK, et al. The impact of disease recurrence on graft survival following liver transplantation: a single centre experience. Transpl Int 2008;21:459-65.

150. Newsome PN. Recurrence of nonalcoholic fatty liver disease after liver transplantation: it is common, but does it affect outcome? Liver Transp/ 2010;16:420-2.

151. Munoz SJ, Deems RO, Moritz MJ, et al. Hyperlipidemia and obesity after orthotopic liver transplantation. Transplant Proc 1991;23:1480-3.

152. Everhart JE, Lombardero M, Lake JR, et al. Weight change and obesity after liver transplantation: incidence and risk factors. Liver Transp/ Surg 1998;4:285-96.

153. Gisbert C, Prieto $\mathrm{M}$, Berenguer $\mathrm{M}$, et al. Hyperlipidemia in liver transplant recipients: prevalence and risk factors. Liver Transp/ Surg 1997;3:416-22.

154. Laryea M, Watt KD, Molinari M, et al. Metabolic syndrome in liver transplant recipients: prevalence and association with major vascular events. Liver Transpl 2007:13:1109-14. 
155. Hanouneh IA, Feldstein AE, McCullough AJ, et al. The significance of metabolic syndrome in the setting of recurrent hepatitis $\mathrm{C}$ after liver transplantation. Liver Transp/ 2008;14:1287-93

156. Painter P, Krasnoff J, Paul SM, et al. Physical activity and health-related quality of life in liver transplant recipients. Liver Transp/ 2001;7:213-19.

157. Stegall MD, Everson G, Schroter G, et al. Metabolic complications after liver transplantation. Diabetes, hypercholesterolemia, hypertension, and obesity. Transplantation 1995;60:1057-60.

158. Navasa M. Bustamante J, Marroni $\mathrm{C}$, et al. Diabetes mellitus after liver transplantation: prevalence and predictive factors. J Hepatol 1996;25:64-71.

159. John PR, Thuluvath PJ. Outcome of patients with new-onset diabetes mellitus after liver transplantation compared with those without diabetes mellitus. Liver Transp/ 2002;8:708-13.

160. Sheiner PA, Magliocca JF, Bodian CA, et al. Long-term medical complications in patients surviving $>$ or $=5$ years after liver transplant. Transplantation 2000;69:781-9.

161. Perseghin G, Mazzaferro V, Benedini S, et al. Resting energy expenditure in diabetic and nondiabetic patients with liver cirrhosis: relation with insulin sensitivity and effect of liver transplantation and immunosuppressive therapy. Am J Clin Nutr 2002; 76:541-8.

162. Tietge UJ, Selberg 0, Kreter A, et al. Alterations in glucose metabolism associated with liver cirrhosis persist in the clinically stable long-term course after liver transplantation. Liver Transp/ 2004:10:1030-40.

163. Merli M, Leonetti F, Riggio 0, et al. Glucose intolerance and insulin resistance in cirrhosis are normalized after liver transplantation. Hepatology 1999;30:649-54.

164. Shields PL, Tang H, Neuberger JM, et al. Poor outcome in patients with diabetes mellitus undergoing liver transplantation. Transplantation 1999;68:530-5.

165. Taler SJ, Textor SC, Canzanello VJ, et al. Hypertension after liver transplantation: a predictive role for pretreatment hemodynamics and effects of isradipine on the systemic and renal circulations. Am J Hypertens 2000;13:231-9.

166. Textor SC, Schwartz L, Wilson DJ, et al. Systemic and renal effects of nifedipine in cyclosporine-associated hypertension. Hypertension 1994;23(Suppl 1):1220-4

167. Galioto A, Semplicini A, Zanus G, et al. Nifedipine versus carvedilol in the treatment of de novo arterial hypertension after liver transplantation: results of a controlled clinical trial. Liver Transp/ 2008;14:1020-8.

168. Neal DA, Brown MJ, Wilkinson IB, et al. Hemodynamic effects of amlodipine, bisoprolol, and lisinopril in hypertensive patients after liver transplantation. Transplantation 2004; 77:748-50.

169. Cross NB, Webster AC, Masson P, et al. Antihypertensives for kidney transplant recipients: systematic review and meta-analysis of randomized controlled trials. Transplantation 2009;88:7-18.
170. Warner FJ, Lubel JS, McCaughan GW, et al. Liver fibrosis: a balance of ACEs? Clin Sci (Lond) 2007;113:109-18.

171. Abu Dayyeh BK, Yang M, Dienstag JL, et al. The effects of angiotensin blocking agents on the progression of liver fibrosis in the HALT-C Trial Cohort. Dig Dis Sci 2011; 56:564-8

172. Dehghani SM, Taghavi SA, Eshraghian A, et al. Hyperlipidemia in Iranian liver transplant recipients: prevalence and risk factors. J Gastroenterol 2007;42: 769-74.

173. Taylor PJ, Kubler PA, Lynch SV, et al. Effect of atorvastatin on cyclosporine pharmacokinetics in liver transplant recipients. Ann Pharmacother 2004;38:205-8.

174. Charlton M. Obesity, hyperlipidemia, and metabolic syndrome. Liver Transp/ 2009 (15 Suppl 2):S83-9.

175. Almutairi F, Peterson TC, Molinari M, et al. Safety and effectiveness of ezetimibe in liver transplant recipients with hypercholesterolemia. Liver Transpl 2009;15:504-8.

176. Nobili V, Pinzani M. Paediatric non-alcoholic fatty liver disease. Gut 2010;59:561-4.

177. Loomba R, Sirlin CB, Schwimmer JB, et al. Advances in pediatric nonalcoholic fatty liver disease. Hepatology 2009;50:1282-93.

178. Schwimmer JB, Deutsch R, Kahen T, et al. Prevalence of fatty liver in children and adolescents. Pediatrics 2006;118:1388-93.

179. Evans HM, Shaikh MG, McKiernan PJ, et al. Acute fatty liver disease after suprasellar tumor resection. J Pediatr Gastroenterol Nutr 2004;39:288-91.

180. Manco M, Bedogni G, Monti L, et al. Intima-media thickness and liver histology in obese children and adolescents with non-alcoholic fatty liver disease. Atherosclerosis 2010;209:463-8.

181. Feldstein AE, Charatcharoenwitthaya P, Treeprasertsuk S, et al. The natural history of non-alcoholic fatty liver disease in children: a follow-up study for up to 20 years. Gut 2009;58:1538-44.

182. Jonas MM, Krawczuk LE, Kim HB, et al. Rapid recurrence of nonalcoholic fatty liver disease after transplantation in a child with hypopituitarism and hepatopulmonary syndrome. Liver Transp/ 2005;11:108-10.

183. Jankowska I, Socha P, Pawlowska J, et al. Recurrence of non-alcoholic steatohepatitis after liver transplantation in a 13-yr-old boy. Pediatr Transplant 2007:11:796-8

184. Evans HM, Kelly DA, McKiernan PJ, et al. Progressive histological damage in liver allografts following pediatric liver transplantation. Hepatology 2006;43:1109-17.

185. Scheenstra R, Peeters PM, Verkade HJ, et al. Graft fibrosis after pediatric liver transplantation: ten years of follow-up. Hepatology 2009;49:880-6.

\section{Gut online}

Visit Gut online and listen to the latest podcast, post comments and download any you might have missed. Keep informed and up to date by visiting gut.bmj.com. 